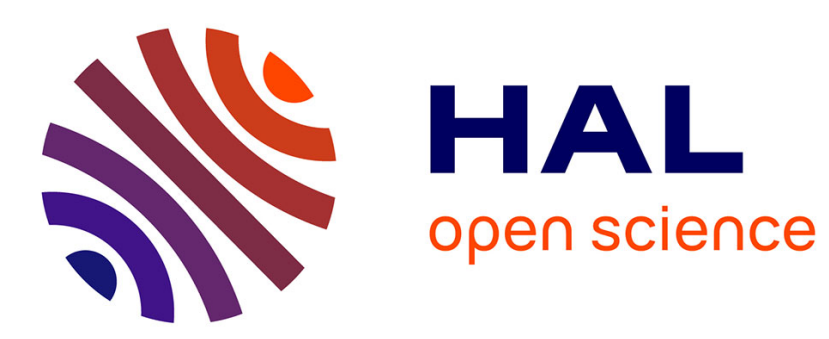

\title{
La figure de Pythagore comme maître d'ésotérisme et de théologie monothéiste dans la philosophie islamique du XIe/XVIIe siècle
}

Mathieu Terrier

\section{- To cite this version:}

Mathieu Terrier. La figure de Pythagore comme maître d'ésotérisme et de théologie monothéiste dans la philosophie islamique du XIe/XVIIe siècle. Revue de l'histoire des religions, 2019, 10.4000/rhr.10218 . hal-02586016

\section{HAL Id: hal-02586016 https://hal.science/hal-02586016}

Submitted on 15 May 2020

HAL is a multi-disciplinary open access archive for the deposit and dissemination of scientific research documents, whether they are published or not. The documents may come from teaching and research institutions in France or abroad, or from public or private research centers.
L'archive ouverte pluridisciplinaire HAL, est destinée au dépôt et à la diffusion de documents scientifiques de niveau recherche, publiés ou non, émanant des établissements d'enseignement et de recherche français ou étrangers, des laboratoires publics ou privés. 


\section{MATHIEU TERRIER}

CNRS, PSL, LEM (UMR 8584)

\section{La figure de Pythagore comme maître d'ésotérisme et de théologie monothéiste dans la philosophie islamique du $\mathrm{XI}^{\mathrm{e}} / \mathrm{XVII}^{\mathrm{e}}$ siècle}

Pythagore est connu en Islam par un corpus de maximes et d'informations mêlant l'authentique et l'apocryphe. L'article étudie la réactivation de cette figure dans l'Iran shî'ite du XI siècle de l'hégire / XVII de notre ère, chez les philosophes Mîr Dâmâd (m. 1040/1631), Mullâ Sadrâ (m. 1045/1636) et Quṭ al-Dîn Ashkevarî (m. ca 1090/1679). Dans leurs ouvres, ils se réfèrent fréquemment à Pythagore comme à un sage initié à la source prophétique, un maître de vie philosophique et religieuse, mais aussi un maître de vérité théologique monothéiste. Par l'harmonisation de l'enseignement qui lui est attribué avec le Coran et les hadîths des Imâms, ces philosophes repensent à nouveaux frais les questions de l'unicité divine, de la relation entre Dieu et Sa création, de l'âme humaine et de son destin.

\section{The Figure of Pythagoras as a Master of Esotericism and Monotheistic Theology in $11^{\text {th }} / 7^{\text {th }}$ - Century Islamic Philosophy}

Pythagoras is known in Islam through a corpus of maxims as well as information mixing the authentic and the apocryphal. The article aims to study the reactivation of this figure in $11^{\text {th }} / 17^{\text {th }}$ century Shî'i Iran, among philosophers such as Mîr Dâmâd (d. 1040/1631), Mullâ Sadrâ (d. 1045/1636) and Quṭb al-Dîn Ashkevarî (d. ca 1090/1679). In their works, they frequently refer to Pythagoras as a wise man initiated at the prophetic source, a master of philosophical and religious life, but also a master of monotheistic theological truth. By harmonizing the teaching attributed to him with the Qur'an and the hadîths of the Imâms, these philosophers rethink questions concerning divine oneness, the relationship between God and His creation, the human soul and its destiny. 
Si la transmission et la réception de la philosophie grecque en Islam ont fait l'objet de nombreuses études, et si les corpus arabes d'Aristote, de Platon, de Plotin et d'Empédocle ont été identifiés, peu d'attention a été prêtée à la figure de Pythagore et à l'ensemble de maximes, philosophèmes, anecdotes, rapportés à lui dans la tradition arabo-musulmane, en particulier audelà de l'âge classique de l'Islam ( $\mathrm{V}^{\mathrm{e}}-\mathrm{VII}{ }^{\mathrm{e}}$ siècles de l'Hégire / $\mathrm{XI}^{\mathrm{e}}-\mathrm{XIII}{ }^{\mathrm{e}}$ siècles de notre ère $)^{1}$. Nous nous intéresserons ici à la présence de Pythagore et de sa voix dans la « renaissance philosophique » en Iran safavide shî‘ite, au XI ${ }^{\mathrm{e}} / \mathrm{XVII}^{\mathrm{e}}$ siècle - une renaissance due, comme Henry Corbin l'a montré, à la rencontre des traditions de la falsafa avicennienne (Ibn Sînâ, m. 428/1037), de la mystique spéculative d'Ibn 'Arabî (m. 538/1240), de la sagesse de l'Ishrâq («illumination ») (hikmat al-ishrâq) de Suhrawardî (m. 587/1191) et de l'enseignement ésotérique attribué aux imâms du shî‘isme duodécimain ${ }^{2}$. Les représentants de ce mouvement seront ici Mîr Dâmâd (m. 1040/1631), Mullâ Șadrâ (m. 1045/1636) et Quṭb al-Dîn Ashkevarî (m. ca. 1090/1679). L'influence du néoplatonisme sur leurs œuvres a souvent été soulignée ${ }^{3}$; mais l'importance du néo-pythagorisme, avec sa figure tutélaire et ses concepts, est restée presque inaperçue ${ }^{4}$. Or cette tendance néo-pythagoricienne, si elle fut largement transmise par le canal néoplatonicien, s'avère irréductible au néoplatonisme ; et la figure de Pythagore, avec ses discours et ses formes de vie, a joué un rôle singulier dans le développement, chez ces penseurs, d'une philosophie proprement shî́ite.

Il ne faut pas s'attendre, dans $1^{\prime} \operatorname{Iran} \mathrm{du} \mathrm{XI}^{\mathrm{e}} / \mathrm{XVII}^{\mathrm{e}}$ siècle, à quelque découverte philologique ou fréquentation directe des textes-sources, mais plutôt à une appropriation active, ou une réactivation créative, d'un corpus textuel conjuguant l'authentique à l'apocryphe. Ce corpus est hérité d'une longue série de doxographies et d'« histoires des sages » allant de la traduction arabe des Placita

\footnotetext{
${ }^{1}$ Anna Izdebska, « Pythagore dans la tradition syriaque et arabe », Dictionnaire des philosophes antiques, dir. Richard Goulet, t. VII, Paris, CNRS Éditions, 2018, p. 860-884.

${ }^{2}$ Henry Corbin, En islam iranien. Aspects spirituels et philosophiques, t. IV, Paris, Gallimard, 1972, p. 9-201; Id., La philosophie iranienne islamique aux XVII ${ }^{e}$ et XVIII ${ }^{e}$ siècles, Paris, Buchet/Chastel, 1981.

${ }^{3}$ Sur Mullâ Șadrâ surtout : Christian Jambet, L'acte d'être. La philosophie de la révélation chez Mollâ Sadrâ, Paris, Fayard, 2002, Index, s.v. « Néoplatonisme», «Platon», «Plotin »; Id., Le gouvernement divin. Islam et conception politique du monde, Paris, CNRS Éditions, 2016 ; Id., La fin de toute chose, suivi de l'Épître du Rassemblement de Mullâ Sadrâ, Paris, Albin Michel, 2017 ; Sajjad Rizvi, Mulla Sadra and Metaphysics: Modulation of Being, Londres, Routledge, 2009 ; Id., « Time and Creation: The Contribution of Some Safavid Philosophies », Revista Portuguesa de Filosofia 62, 2006, p. 713-737 ; Id., « Philosophy as a Way of Life in the World of Islam: Applying Hadot to the Study of Mullā Șadrā Shīrāzī », Bulletin of the School of Oriental and African Studies, 2012, p. 1-13.

${ }^{4}$ À mentionner, sur la période antérieure, Matthew Melvin-Koushki, «The New Brethren of Purity: Ibn Turka and the Renaissance of Neo-Pythagoreanism in Early Modern Iran », Brill's Companion to the Reception of Pythagoras and Pythagoreanism in the Middle Ages and the Renaissance, éd. Irene Caiazzo, Constantinos Macris et Aurélien Robert, Leyde, Brill, à paraître.
} 
philosophorum du Pseudo-Plutarque à la Promenade des esprits (Nuzhat al-arwaḥ) de l'Ishrâqî Shams al-Dîn al-Shahrazûrî (m. avant 704/1305) ${ }^{5}$. Dans les figures des sages grecs représentées par ces sources, les philosophes shî́ites du XI ${ }^{\mathrm{e}} / \mathrm{XVII}^{\mathrm{e}}$ siècle se montrent particulièrement sensibles à la double dimension, théorique et pratique. Pythagore en particulier, maître de vie et maître de vérité, leur apparaît comme l'idéal-type du sage monothéiste originel et le parent transhistorique du « guide divin » qu'est l'Imâm, figure tutélaire et axiale du shî‘isme, à commencer par le premier imâm ‘Alî b. Abî Ṭâlib (m. 40/661) .

Pythagore se voit ainsi convoqué par ces philosophes shî‘ites pour traiter des thèmes et problèmes majeurs, identiquement théologiques et philosophiques, qui étaient les leurs : l'unicité de Dieu, sa relation à ses attributs et à sa création ; 1'homme parfait et son rapport au(x) monde(s) ; l'origine et le retour à Dieu. Les pages suivantes présenteront ces aspects successifs de la vie et de la pensée de Pythagore reflétés par la renaissance de la philosophie islamique.

\section{PyTHAgore, SAGE INITIE, MAITRE D’ESOTERISME ET SAINT MARTYR}

\section{L'initiation prophétique}

Les ouvrages arabo-musulmans retraçant l'histoire des sages avant l'islam mentionnent Pythagore dans deux listes prestigieuses. La première, provenant de la Doxographie du Pseudo-

\footnotetext{
${ }^{5}$ Sur ces ouvrages, nous nous permettons de renvoyer à Mathieu Terrier, Histoire de la sagesse et philosophie shi'ite. "L'Aimé des cœurs » de Quṭ al-Dīn Aškevarī, Paris, Le Cerf, 2016, p. 124-137 ; Id., "Histoire de l'histoire de la sagesse en islam. Résumé des conférences 2015-2016 », Annuaire de l'École Pratique des Hautes Études. Section des Sciences Religieuses, t. 124, 2015-2016 [2017], p. 363-372, en ligne, URL : http://journals.openedition.org/asr/1652 ; Id., «Histoire de l'histoire de la sagesse en islam. Résumé des conférences 2016-2017 », Annuaire de l'École Pratique des Hautes Études. Section des Sciences Religieuses, t. 125, 2016-2017 [2018], p. 395-404, en ligne, URL: https://journals.openedition.org/asr/2115. Dans cet article, nous n'analyserons pas les canaux de transmission des informations sur Pythagore jusqu'à nos penseurs, mais ferons seulement état des sources arabes les plus anciennes et de certaines correspondances dans les sources grecques. Sur la vie de Pythagore dans les sources arabes médiévales, voir Emily Cottrell, "Notes sur quelques-uns des témoignages médiévaux relatifs à l'Histoire philosophique de Porphyre », Islamic Thougt in the Middle Ages. Studies in Text, Transmission and Translation, in Honor of Hans Daiber, éd. Anna Akasoy et Wim Raven, Leyde, Brill, 2008, p. 523-555 ; Ead., « Pythagoras, the Wandering Ascetic: A Reconstruction of the Life of Pythagoras According to al-Mubashshir Ibn Fātik and Ibn Abī Ușaybi 'a », Pythagorean Knowledge from the Ancient to the Modern World: Askesis, Religion, Science, éd. Almut-Barbara Renger et Alessandro Stavru, Wiesbaden, Harrassowitz, 2016, p. 467-517.

${ }^{6}$ Sur la figure de l'imâm et de 'Alî en particulier dans le shî́isme, voir notamment Mohammad Ali Amir-Moezzi, Le Guide divin dans le shī isme originel. Aux sources de l'ésotérisme en islam, Lagrasse, Verdier, 1992 [réimpr. 2007] ; Id., La preuve de Dieu. La mystique shi'ite selon al-Kulaynî (III'/Xe siècle), Paris, Le Cerf, 2018.
} 
Ammonios (III/IX ${ }^{\mathrm{e}}$ siècle), reprise et modifiée par 'Abd al-Karîm al-Shahrastânî dans son Livre des religions et des sectes (Kitâb al-milal wa l-niḥal), est celle des sept «piliers de la sagesse » (asâțîn al-hikma): Thalès, Anaxagore, Anaximène, Empédocle, Pythagore, Socrate et Platon ${ }^{7}$. La seconde, remontant au Livre du terme de l'éternité (Kitâb al-Amad 'alâ l-abad) du philosophe al‘Âmirî (m. 381/992), et reprise notamment par le Qâdî Șâ‘id al-Andalusî (m. 462/1070) dans ses Catégories des nations (Tabaqât al-umam), rassemble cinq sages ayant embrassé la totalité de la sagesse avant sa division en disciplines et sectes : Empédocle, Pythagore, Socrate, Platon, Aristote $^{8}$. Dans le Livre du terme de l'éternité, on lit pour la première fois qu'Empédocle et Pythagore ont été initiés, le premier par Luqmân, compagnon du prophète David et récipiendaire de la sagesse de Dieu (Coran, XXXI, 12), le second par Salomon ou ses proches compagnons ; et que tous deux ont tiré leur sagesse de la «niche aux lumières de la prophétie » (mishkât alnubuwwa), en référence au fameux verset XXIV, 35 du Coran : " Dieu est la lumière des cieux et de la terre! Sa lumière est comparable à une niche où se trouve une lampe... »9.

Mîr Dâmâd, dans son ouvrage en persan Tisons ardents et temps fixés (Jadhawât wa mawâqût), a ce récit à l'esprit quand il présente Pythagore comme «l'imâm des sages (imâm-e hokamâ) de Samos qui, du temps du prophète Salomon, prit la sagesse à la niche de la révélation et à la mine de la prophétie (ma'dan-e nobovvat) ${ }^{10}$. Pythagore apparaît d'emblée comme un imâm, non seulement au sens générique de « chef » ou « guide », mais bien au sens shî‘ite de « guide divin ».

Mullâ Șadrâ, dans son traité Sur la nouveauté du monde (hudûth al- 'âlam), donne du récit le développement suivant :

\footnotetext{
${ }^{7}$ Sur cette «pseudo-doxographie » élaborée en milieu shî‘ite hétérodoxe, voir Ulrich Rudolph, Die Doxographie des Pseudo-Ammonios. Ein Beitrag zur Neuplatonischen Überlieferung im Islam, Stuttgart, Franz Steiner, 1989 ; Id., « La connaissance des Présocratiques à l'aube de la philosophie et de l'alchimie islamiques », L'alchimie et ses racines philosophiques, éd. Cristina Viano, Paris, Vrin, 2005, p. 155-170 ; Daniel De Smet, «Les philosophes grecs, tous monothéistes ! Une relecture néoplatonicienne islamisée de l'histoire de la philosophie (Pseudo-Ammonius) », dans ce dossier. Pour les sept piliers de la sagesse, voir Rudolph, Pseudo-Ammonios, XIII, 1, p. 48-49; seuls Thalès et Anaximène sont mentionnés parmi les sept, mais on peut supposer que les autres sont Empédocle, Pythagore, Anaxagore, Héraclite, Démocrite ou Xénophane. Pour la liste des sept mentionnée supra, voir 'Abd al-Karîm Shahrastânî, Kitâb al-milal wa-l-niḥal, éd. Muḥammad b. Fatḥ Allâh Badrân, Le Caire, Maktabat al-anglûl-mișriyya, 1366/1947, p. 65 ; Id., Livre des religions et des sectes, II, trad. fr. Jean Jolivet et Guy Monnot, Louvain, Peeters/Unesco, 1993, p. 179.

${ }^{8}$ Everett Rowson, A Muslim Philosopher on the Soul and Its Fate: Al-'Ämirī's Kitāb al-Amad 'alā-l-abad, New Haven, American Oriental Society, 1988, p. $70-75$ (texte arabe et trad.) ; Șâ‘id al-Andalusî (m. 462/1070), Kitâb Tabaqât al-umam, éd. Louis Cheikho, Beyrouth, al-Maktaba al-kâthûlîkiyya li-l-âbâ’ al-yasû'iyyîn, 1912, p. 21-27 ; Id., trad. fr. Régis Blachère (Livre des Catégories des nations), Paris, Larose, 1935, p. 58-69.

${ }^{9}$ Le Coran est cité dans la traduction de Denis Masson, Paris, Gallimard, 1967, légèrement modifiée par endroits.

${ }^{10}$ Mîr Dâmâd, Jadhawât wa mawâqît, éd. 'Alî Awjabî, Téhéran, Mirâth-e maktûb, 1380 h.s./2001, p. 46.
} 
[Après les Milésiens Thalès et Anaxagore], le second principe du levain de la philosophie (khamîrat al-falsafa) la plus mûre, la plus parfaite, la plus élevée et la plus lumineuse, provient de Pythagore, fils de Mnésarque, originaire de l'île de Samos. On dit que c'est lui qui qualifia la philosophie par ce nom signifiant l'amour de la science (mahabbat al- 'ilm) ${ }^{11}$. Il avait rencontré des disciples de Salomon fils de David en Égypte et s'était instruit auprès d'eux. Il pénétra dans les temples des hommes pratiquant l'autodéification et l'exercice [spirituel] (al-muta'allihîn al-murtâdîn), ordonnant pour eux d'importants exercices et combats spirituels (riyậât wa mujâhadât) ainsi que des sciences exactes qu'ils contemplaient venant de lui. Nul homme n'était autorisé à entrer dans [ces temples] sinon le phénix de son temps. [Pythagore] fut aussi l'élève de l'éminent sage divin Empédocle qui avait reçu son instruction de Luqmân, lequel avait reçu la sienne du prophète David. Puis Socrate reçut son instruction de Pythagore, Platon reçut la sienne de Socrate et Aristote reçut la sienne de Platon ${ }^{12}$.

Mullâ Șadrâ interprète ici les deux traditions ionienne et italique comme les deux « levains de la philosophie », là où Suhrawardî voyait les deux «levains de la sagesse » dans les traditions grecque et perse ${ }^{13}$. Pythagore, à l'origine de la seconde en vertu de son initiation orientale, est associé à deux notions paradigmatiques de la représentation de la sagesse ancienne : l'assimilation au divin ( $t a$ 'alluh), équivalent de l'homoiôsis theôi, et les exercices spirituels (riyậ̂ât), également fondamentales dans la représentation que la philosophie islamique donne d'elle-même.

Ashkevarî, dans son histoire des sages allant d'Adam à son maître Mîr Dâmâd, intitulée L'Aimé des cours (Maḥbûb al-qulûb), consacre une longue notice à Pythagore, appelé «le sage autodéifié » (al-hakîm al-muta'allih $)^{14}$. Il rapporte que celui-ci vécut à l'époque de Salomon fils de David, quelque temps après Empédocle, et prit la sagesse à la «mine de la prophétie » en Égypte après être passé par la Syrie (bilâd al-shâm) ; c'est aussi des Égyptiens qu'il apprit la géométrie. Puis il retourna en Grèce, apportant à son peuple la géométrie, la physique, mais aussi la « science de la religion » ('ilm al-dîn $)^{15}$. Plus tôt, dans sa notice sur Hermès, il mentionne Pythagore comme

11 Ces informations proviennent de la doxographie du Pseudo-Plutarque: Hans Daiber, Aetius arabus. Die Vorsokratiker in arabischer Überlieferung, Wiesbaden, Franz Steiner, 1980, I, 3, 7-8, p. 100. - Shahrastânî, Milal, II, p. 62 (Religions et sectes, II, p. 175), écrit « l'amour de la sagesse » (mahabbat al-hikma).

${ }^{12}$ Mullâ Șadrâ, Risâla Hudûth al- 'âlam, éd. et trad. pers. Moḥammad Khwâjavî, Téhéran, Intishârât-e Mowlâ, 1377 h.s./1998-99, p. 273. Toutes les traductions des textes présentés sont nôtres.

${ }^{13}$ Shihâb al-Dîn Suhrawardî, Kitâb al-mashâri ' wa-l-muṭ̂arahât, Id., Euvres philosophiques et mystiques, éd. Henry Corbin, Téhéran, Institut d'études et de recherches culturelles, 2001, p. 503. Voir là-dessus John Walbridge, The Leaven of the Ancients, New York, State University of New York Press, 2000 ; le compte-rendu très critique de cet ouvrage par Dimitri Gutas, «Suhrawardī and Greek Philosophy », Arabic Sciences and Philosophy 13, 2003, p. 303309 ; et la défense de l'hypothèse d'une « ligne d'enseignement gnostique secret » conduisant de Pythagore aux soufis dans Peter Kingsley, Empédocle et la tradition pythagoricienne. Philosophie ancienne, mystère et magie, trad. fr. Grégoire Lacaze, Paris, Les Belles Lettres, 2010, p. 447-450 (original anglais 1995).

${ }^{14}$ Quṭb al-Dîn Ashkevarî, Maḥbûb al-qulûb, vol. 1 (al-maqâla al-ûlâ), éd. Ibrâhîm al-Dîbâjî et Aḥmad Șidqî, Téhéran, Mirâth-e maktûb, 1378 h.s./1999, p. 208-236 ; M. Terrier, Histoire de la sagesse, p. 373-420.

15 Ashkevarî, Maḥbûb, p. 208-209. 
disciple du deuxième Hermès, philosophe et médecin, expert dans la science du nombre, ayant vécu à Babel en Chaldée après le Déluge ${ }^{16}$.

Les voyages initiatiques de Pythagore évoqués par les sources grecques, Porphyre en tête ${ }^{17}$, se voient donc insérés dans un récit hiéro-historique soutenant l'accord foncier de la philosophie grecque et de la Révélation, le Coran scellant toutes celles des précédents prophètes. En termes historiques, ce récit contient des ambiguïtés (Pythagore a-t-il été disciple de Salomon lui-même ou seulement de ses compagnons ?), des confusions (Empédocle antérieur à Pythagore ${ }^{18}$ ) et des aberrations (Empédocle et Pythagore rejetés au $\mathrm{X}^{\mathrm{e}}$ siècle avant notre ère, période supposée de David et Salomon, tout en étant liés à Socrate, Platon et Aristote). Elles ne troublent pas les philosophes shî‘ites, dont les spéculations métaphysiques et théologiques font fi de toute critique historique ou philologique. Leur souci n'est pas d'établir ou de réfuter des faits d'histoire de la philosophie mais de construire une représentation de la sagesse, de son devenir et de sa pérennité, dont ils puissent se penser les héritiers. Dans cette représentation de l'histoire sainte et sapientiale, Pythagore joue un rôle-clé en connectant la chaîne initiatique des philosophes à la tradition des prophètes.

\section{L’expérience mystique}

Avec cette initiation à la « niche aux lumières de la prophétie », les récits grecs pythagoriciens des expériences visionnaires du maître, transmis et adaptés par l'historiographie arabomusulmane, prennent un sens nouveau chez les philosophes shî‘ites. Ashkevarî rapporte :

On prétend qu'il contempla les mondes par ses sens et son intuition, poussa l'exercice spirituel jusqu'à entendre le bruissement de la sphère et atteindre la station de l'ange. Il dit : « Je n'ai jamais rien entendu de plus agréable que les mouvements [de la sphère], rien vu de plus splendide que ses formes

\footnotetext{
16 Ibid., p. 164 ; l'information provient d'Ibn Abî Ușaybi'a, 'Uyûn al-anbâ' fî tabaqât al-ațibbâ', éd. Muhamamad Bâsil 'Uyûn al-Sûd, Beyrouth, Dâr al-kutub al-'ilmiyya, 1419/1998, p. 24.

${ }^{17}$ Porphyre, Vie de Pythagore, éd. et trad. fr. Édouard Des Places, Paris, Les Belles Lettres, 1982, § 6, p. 38, et §§ 1112, p. 41, mentionne une initiation auprès des Égyptiens, des Chaldéens, des Phéniciens, mais aussi, concernant les « rituels des dieux », des Mages perses. Parallèles dans Jamblique, Vie de Pythagore, trad. fr. Luc Brisson et AlainPhilippe Segonds, Paris, Les Belles Lettres, $2011^{2}$ [], § 13-19, p. 12-15; Diogène Laërce, Vies et doctrines des philosophes illustres, VIII, 3, trad. fr. dans Marie-Odile Goulet-Cazé (dir.), Paris, Librairie Générale Française, 1999, p. 941-942. Cf. Constantinos Macris, «Pythagore de Samos », Dictionnaire des philosophes antiques, dir. Richard Goulet, t. VII, Paris, CNRS Éditions, 2018, p. 681-850, ici p. 787-792.

${ }^{18}$ Daniel De Smet, Empedocles Arabus. Une lecture néoplatonicienne tardive, Bruxelles, Koninklijke Academie voor Wetenschappen, Letteren en Schone Kunsten, 1998, p. 123.
} 
et ses aspects ». Il déduisit avec son intelligence la science de la musique ( 'ilm al-mûsîqâ), la subordonna aux rapports numériques et prétendit l'avoir tirée de la niche aux lumières de la prophétie. [...]

Pythagore dit : «J'ai contemplé ces mondes supérieurs par mes sens après l'exercice spirituel. Je me suis élevé du monde des natures au monde de l'Âme, puis au monde de l'Intellect. J'y ai contemplé les formes immatérielles dans leur beauté, leur lustre et leur lumière ; j'ai entendu leurs nobles accents, leurs voix mélodieuses et spirituelles $»^{19}$.

Si le premier rapport semble critiquer la prétention pythagoricienne à une origine prophétique de la science harmonique en l'attribuant à sa spéculation propre ${ }^{20}$, le second valide la vision et l'audition spirituelles de Pythagore par l'autorité de son témoignage personnel. L'expérience extatique de Pythagore fournit une vérification empirique à la hiérarchie néoplatonicienne des hypostases : l'Intellect, l'Âme, la Nature. Elle évoque aussi l'ascension céleste attribuée au prophète Muhammad, pointant vers une interprétation philosophique de celle-ci ${ }^{21}$.

Mîr Dâmâd assimile l'expérience de Pythagore à un voyage dans le « monde de l'Image » ou « monde imaginal » ( 'âlam al-mithâl), intermédiaire entre l'intelligible et le sensible. Élaboré par les disciples de Suhrawardî, ce concept désigne en particulier, chez nos philosophes, « le monde où se spiritualisent les corps et se corporalisent les esprits », où les événements de l'histoire sainte et des récits eschatologiques trouvent leur réalitée ${ }^{2}$. Mîr Dâmâd fait remonter l'origine de cette conception à un étrange groupe de philosophes syncrétiques :

Un groupe de stoïciens pythagoriciens et platoniciens (revâqiyyeh-ye fithâgûrisiyyîn va aflâtûniyyîn), ainsi qu'un groupe de [philosophes] illuministes de l'islam (eshrâqiyyeh-ye eslâmiyyîn), ont attesté un monde intermédiaire entre le monde du Mystère (ghayb), qui est le monde intelligible, et le monde du Témoignage (shahâdat), qui est le monde sensible. Ce monde, ils l'ont appelé Hûrqalyâ, monde de l'Image, monde du Témoignage joint, monde des spectres (ashbâh), monde de l'isthme (barzakh), huitième climat, terre de la vérité et imagination séparée (khayâl munfașal), quand l'imagination humaine est une imagination conjointe [au sujet] (khayâl muttașil). [...] Ils disent que Jâbalqâ et Jâbalsâ sont d'immenses cités de ce monde ${ }^{23}$, que l'affaire de la résurrection corporelle, les promesses des

\footnotetext{
${ }^{19}$ Ashkevarî, Mahbûb, p. 209 et 235. Cf. Porphyre, Vie de Pythagore, § 30, p. 50. Sur l'importance de cette tradition dans le néoplatonisme, voir Dominic O’Meara, « Hearing the Harmony of the Spheres in Late Antiquity », A Platonic Pythagoras. Platonism and Pythagoreanism in the Imperial Age, éd. Mauro Bonazzi, Carlos Lévy et Carlos Steel, Turnhout, Brepols, 2007, p. 147-161.

${ }^{20}$ Conformément au rapport de Jamblique, Vie de Pythagore, § 114-121, p. 65-69.

${ }^{21}$ Éric Geoffroy, «Ascension céleste », Dictionnaire du Coran, dir. Mohammad Ali Amir-Moezzi, Paris, Robert Laffont, 2007, p. 95-99. Pour un exemple d'interprétation philosophique shî‘ite, voir Christian Jambet, « L'Homme parfait. Métaphysique de l'âme et eschatologie selon Qāẓ̂̀ Sa ‘̄id Qummī », Annuaire de l'École Pratique des Hautes Études. Section des Sciences Religieuses, t. 125, 2016-2017, p. 411-423, ici p. 417-418.

${ }^{22}$ L'expression entre guillemets est de Muhsin Fayḍ Kâshânî (m. 1090/1679) : voir Henry Corbin, Corps spirituel et terre céleste, Paris, Buchet/Chastel, 1979, p. 206-210.

${ }^{23}$ Sur ces lieux, voir H. Corbin, Ibid., p. 82-134; Daniel De Smet, « Les cités merveilleuses de Ğābalqā, Ğābarsā et Hūrqālyā. Du "monde des images en suspens" de Šihāb al-Dīn al-Suhrawardī au Mundus imaginalis d'Henry Corbin »,
} 
prophéties, les récompenses et les châtiments corporels [...], décrits en détails par la Sainte Révélation et les paroles des prophètes, sont avérés dans [ce monde], car le corps imaginal (badan-e methâlî) tient lieu du corps sensible dans tous ces jugements. Il en va de même dans les rêves, les miracles merveilleux, les événements extraordinaires, le parcours instantané des distances, l'ubiquité, etc. On rapporte par exemple que le Prince des croyants, l'héritier de l'envoyé du Seigneur, 'Alî, se trouvait un soir du mois de Ramadan hôte de quelques compagnons, rompant le jeûne avec eux dans leurs demeures. Puis [le Prophète] déclara : "Ce soir, 'Alî était dans ma maison et a rompu le jeûne avec moi ».

De Pythagore, on rapporte qu'il ôtait parfois sa robe corporelle et rejetait le monde des sens. Il se connectait aux cieux, parvenait à la station de l'ange, entendait le bruissement de la sphère. Puis il retournait dans le climat de la Nature et la cité du Mélange, et il disait : «Je n'ai jamais rien entendu de plus agréable que les mouvements [de la sphère], rien vu de plus splendide que ses formes et ses figures $»^{24}$.

L'assimilation des pythagoriciens, des platoniciens et même des «illuministes » de l'islam (ishrâqiyyûn) à des stoïciens demeure à notre sens mystérieuse ${ }^{25}$. L'intéressant est que Mîr Dâmâd attribue aux pythagoriciens deux idées «modernes », la division du système de l'être en trois mondes - sensible, imaginal et intelligible - et l'homologation du deuxième monde à l'« imagination séparée » d'Ibn 'Arabîi ${ }^{26}$. Il interprète l'expérience de Pythagore dans les termes de la mystique philosophique de Suhrawardî - « le rejet de la robe du corps », devenu un topos de la gnose philosophique ${ }^{27}$-, et lui confère la même réalité, dans le même monde, qu'aux avertissements prophétiques et aux prodiges des saints. Plus encore, il rapproche explicitement la puissance spirituelle de Pythagore du pouvoir surnaturel de l'imâm 'Alî, illustré ici par son don d'ubiquité, associé aux « prodiges » (karâmât) des saints soufis ; il suggère ainsi une parenté entre la « sagesse divine » antique, la « hiéro-intelligence » imâmite et la sainteté soufie ${ }^{28}$. Remarquons enfin la conclusion nostalgique du récit avec l'évocation du retour de Pythagore au plan inférieur de la Nature : elle rappelle la fin du récit d'extase de Plotin (Ennéades, IV, 8, 1) traduit dans la Théologie du Pseudo-Aristote ${ }^{29}$. Mîr Dâmâd reprend la même trame - extase ou dépouillement du

Décrire, nommer ou rêver les lieux en Orient. Géographie et toponymie entre réalité et fiction: Jean-Marie Kuchten in memoriam, dir. Christian Cannuyer, Bruxelles, Société belge d'études orientales, 2011, p. 133-154.

${ }^{24}$ Mîr Dâmâd, Jadhawât, p. 62-64.

${ }^{25}$ Mullâ Șadrâ, Kitâb al-mashâ 'ir, éd. Fâtin Muhammad Khalîl al-Labawî, Beyrouth, Mu'assasat al-ta'rîkh al-'arabî, 1420/2000, p. 84, qualifie Suhrawardî et les Ishrâqîs de «continuateurs des stoïciens ». Voir là-dessus le développement très spéculatif de J. Walbridge, The Leaven of the Ancients, p. 187-197.

${ }^{26}$ Sur la distinction d'Ibn 'Arabî entre imagination conjointe et imagination séparée, voir Henry Corbin, L'imagination créatrice dans le soufisme d'Ibn 'Arabî, Paris, Médicis-Entrelacs, 2006 [1 éd. 1958], p. 232-233.

${ }^{27}$ Voir Suhrawardî, Kitâb al-mashâri', p. 503.

${ }^{28}$ Sur la Science sacrée ('ilm) et la hiéro-intelligence (' $a q l$ ) dans le shî‘isme imâmite, voir M. A. Amir-Moezzi, Le Guide divin, p. 174-199 ; Id., La Preuve de Dieu, p. 159-270, passim ; sur les prodiges dans le soufisme, voir Kadhim Jihad, Le Livre des prodiges. Anthologie des Karâmât des saints de l'islam, Arles, Sindbad-Actes Sud, 2003.

${ }^{29}$ Cf. Uthûlûjiyâa Arisțâtâlîs, dans Aflûțîn 'inda l- 'Arab - Plotinus apud Arabes, éd. 'Abd al-Raḥmân Badawî, Kuwayt, Wikâlat al-mațbû'ât, 1977, p. 22. 
corps, pérégrinations de l'esprit dans les mondes supérieurs, rechute dans la nature - dans un récit d'extase personnel rapporté par son disciple Ashkevarî à la fin de son histoire des sages ${ }^{30}$. Pour les philosophes shî‘ites du XI $\mathrm{XI}^{\mathrm{e}} / \mathrm{XVII}^{\mathrm{e}}$ siècle comme pour les pythagoriciens de l'antiquité tardive, Pythagore n'était donc pas une figure mythique ou un personnage conceptuel, mais bien un précurseur historique et une source d'inspiration vive.

\section{La sagesse ésotérique}

Les philosophes shî‘ites se représentent volontiers la philosophie antique comme une discipline impliquant une éthique du secret, un langage symbolique et une activité herméneutique, à l'instar de l'enseignement de leurs imâms et de l'idée qu'ils se font de leur propre activité. Dans l'introduction de son histoire, Ashkevarî affirme ainsi que l'usage de s'exprimer en « symboles et énigmes » (rumûz wa alghâz) est commun aux sages anciens et aux prophètes et imâms ${ }^{31}$. Dans sa notice sur Pythagore, il présente l'enseignement de celui-ci sous un double aspect : exotérique, avec la rédaction de nombreux livres d'arithmétique et de musique ${ }^{32}$; ésotérique, avec l'emploi de «symboles et énigmes », traductions-adaptations des symbola transmis par Porphyre et Jamblique $^{33}$ :

Quand quelqu'un venait à lui pour écouter son discours, [Pythagore] s'adressait à lui ou bien par l'argumentation et l'instruction, ou bien par le sermon et le conseil. Il exprimait sa sagesse de façon symbolique et voilée. Parmi ses symboles et énigmes : "Ne passe pas au-dessus de la balance », autrement dit, évite l'excès et la démesure ${ }^{34}$; «Ne tisonne pas le feu avec le couteau, car il pourrait s'embraser une nouvelle fois », autrement dit, évite d'exciter par tes paroles un homme en colère ${ }^{35}$. « $\mathrm{Ne}$ t'assieds pas sur la pauvreté $(f a q r)^{36} »$, autrement dit, ne vis pas dans l'oisiveté ; [...] «On ne jette pas

\footnotetext{
${ }^{30}$ Voir H. Corbin, En islam iranien, t. IV, p. 9-53 ; Mathieu Terrier, « Mīr Dāmād (m. 1041/1631), philosophe et mujtahid. Autorité spirituelle et autorité juridique en Iran safavide sh̄̄ 'ite », Studia Islamica 113, 2018, p. 121-165, ici p. 152-156.

${ }^{31}$ Ashkevarî, Mahbûb, p. 124 ; Terrier, Histoire de la sagesse, p. 211-212 et 237-239.

${ }^{32}$ Ashkevarî, Mahbûb, p. 215 et 217, attribuant 280 ouvrages à Pythagore. Sur les œuvres pseudépigraphiques attribuées à Pythagore dans la tradition grecque, voir C. Macris, «Pythagore », p. 819 et 843-850, et dans la tradition arabe, A. Izdebska, « Pythagore », p. 860-861.

${ }^{33}$ Sur les traductions arabes des symbola pythagoriciens, voir A. Izdebska, «Pythagore », p. 868-869.

${ }^{34}$ Cf. Porphyre, Vie de Pythagore, § 42, p. 55 ; parallèles dans Jamblique, Vie de Pythagore, § 186, p. 102 ; Id., Protreptique, éd. et trad. fr. Édouard Des Places, Paris, Les Belles Lettres, 1989, chap. 21, n 13, p. 133 et 140 ; Diogène Laërce, Vies et doctrines, VIII, 17-18, p. 954 et 956 ; Clément d'Alexandrie, Stromates, V, éd. et trad. fr. Alain Le Boulluec et Pierre Voulet, Paris, Le Cerf, 1981, p. 72-73.

${ }^{35}$ Cf. Porphyre, Vie de Pythagore, § 42, p. 55 ; Jamblique, Vie de Pythagore, § 227, p. 121 ; Id., Protreptique, 21, $\mathrm{n}^{\circ}$ 8, p. 133 et 138-139; Diogène Laërce, Vies et doctrines, VIII, 17-18, p. 954-957.

${ }^{36}$ Cf. Porphyre, Vie de Pythagore, § 42, p. 55 ; Jamblique, Protreptique, 21, n 18, p. 134 et 142-143; Diogène Laërce, Vies et doctrines, VIII, 17, p. 954.
} 
le fardeau sur le porteur mais on aide celui-ci à le porter », autrement dit, que nul ne néglige ses propres actions en matière de vertus et d'obéissance [à Dieu] ${ }^{37} ;$ « Ne mets pas des images des anges sur les chatons de tes bagues », autrement dit, ne divulgue pas aux ignorants tes intentions quant aux secrets des sciences divines ${ }^{38}$.

Une autre parole énigmatique aurait été gravée sur la bague de Pythagore, en vertu d'une coutume communément attribuée aux sages grecs dans les histoires de la sagesse en islam ${ }^{39}$. Ce symbole donne lieu à une interprétation d'esprit ascétique et gnostique :

L'inscription portée sur sa bague était : «Un mal qui ne dure pas vaut mieux qu'un bien qui ne dure pas » [...] L'explication en est qu'un mal interrompu suivi d'un bien durable vaut mieux qu'un bien interrompu suivi d'un mal durable. L'intention est d'inciter à préférer la vie subsistante à la vie évanescente, à corriger les affaires de la vie dernière, qui sont durables et ininterrompues ${ }^{40}$.

À ce registre ésotérique appartiennent aussi, dans une moindre mesure, des fragments des Vers d'or qu'Ashkevarî rapporte dans sa gnomologie de Pythagore sans les rapporter à l'ensemble connu en arabe sous le titre des « Recommandations en or » (al-waşâyâ al-dhahabiyya $)^{41}$ :

«Garde-toi de commettre aucune action hideuse, que tu sois seul ou avec un autre. Que ta honte de toi-même soit plus forte que ta honte de tout autre »; «Que ton but dans la fortune soit de l'acquérir et de la dépenser de façon licite »; «Quand tu entends un mensonge, calme ton âme pour le supporter» $[\ldots] ;$ « Réfléchis avant d'agir $»^{42}$.

\section{La règle de vie philosophique et religieuse}

\footnotetext{
${ }^{37}$ Porphyre, Vie de Pythagore, $\S 42$, p. 55-56, donne l'inverse : « ne pas aider à décharger un fardeau, mais aider à le charger », tout comme Jamblique, Vie de Pythagore, § 84, p. 48 ; Id., Protreptique, 21, n 10, p. 133. La version donnée ici correspond en revanche à celle de Diogène Laërce, Vies et doctrines, VIII, 17, p. 954-955.

${ }^{38}$ Cf. Porphyre, Vie de Pythagore, $\S 42$, p. 56 ; Jamblique, Vie de Pythagore, $\S 84$, p. 48 et $\S 256$, p. 137 ; Id., Protreptique, $\mathrm{n}^{\circ} 23$, p. 134 et 145-146; Diogène Laërce, Vies et doctrines, VIII, 17, p. 955, qui parlent d'images des dieux ; Clément, Stromates, V, 28, 2, p. 70-71. Tout le paragraphe : Ashkevarî, Maḥbûb, p. 217.

${ }^{39}$ Ḥunayn b. Isḥâq, Âdâb al-falâsifa ikhtașarahu Muhammad b. Muhammad al-Anșarî̀, éd. A. Badawi, Kuwayt, Ma'had al-makhțuṭ̂t al-'arabiyya, 1406/1985, p. 45-47 ; Ashkevarî, Mahbbûb, p. 163-164 (Hermès), 182 (Hippocrate), 194 (Galien), 217 (Pythagore), 242 (Socrate), 259 (Platon), 281 (Aristote), 340 (Solon); M. Terrier, Histoire de la sagesse, p. 294, 326, 343, 384, 427, 457, 494, 602.

${ }^{40}$ Ashkevarî, Maḥbûb, p. 217.

${ }^{41}$ Sur les traductions arabes des Vers d'or pythagoriciens, attribués à Pythagore lui-même, voir A. Izdebska, « Pythagore », p. 862-865. Nous trouverons une autre citation, explicite celle-là, des Vers d'or chez Mullâ Șadrâ ; voir infra p. 29.

${ }^{42}$ Ashkevarî, Maḥbûb, p. 220 et 222. Cf. Hiéroclès d'Alexandrie, Commentaire sur les Vers d'or des pythagoriciens, introd. et trad. fr. Noël Aujoulat et Adrien Lecerf, Paris, Les Belles Lettres, 2018, p. 83-84, v. 11-12, 16, 21-23, 27. Les sources arabes des Vers d'or sont Ḥunayn b. Isḥâq, Âdâb, p. 116-117; al-Sijistânî (attribué à), Muntakhab Șiwân al-hikma, éd. 'Abd al-Raḥmân Badawî, Téhéran, Bonyâd-e farhangi-ye Îrân, 1974, p. 120 et 122 ; Id., éd. Douglas M. Dunlop, The Hague, Mouton, 1979, p. 32-33.
} 
Avant d'être un théoricien, le Pythagore des philosophes musulmans et shî‘ites en particulier est un maître de vie philosophique et religieuse. Conformément au propos de Platon dans la République (X,600b), il apparaît comme le fondateur d'une règle de vie et d'une éducation distinguant ses disciples du reste des hommes. Ashkevarî en rapporte les principaux articles. Certains sont sans rapport évident avec l'éthique islamique : s'abstenir de tout contact avec un animal tué et son tueur, pratiquer l'amitié dans l'enseignement des sciences célestes, mettre en commun tous les biens entre amis ${ }^{43}$. D'autres consonnent littéralement avec des valeurs positives de l'éthique islamique, soufie et shî'ite : le voyage (siyâha), la purification des sens (taqdîs alhawâss), l'impeccabilité des âmes ( 'iṣmat al-nufûs), l'acquittement du combat spirituel (iqâmat al-jihâd), la multiplication du jeûne (ikthâr al-șiyâm). Conséquence de cette discipline et signe de sa perfection, ce trait de comportement exceptionnel de Pythagore : il ne se réjouissait ni ne s'affligeait jamais outre mesure, nul ne le vit jamais rire ni pleurer ${ }^{44}$. Ashkevarî voit dans cette impassibilité du «sage gnostique » (al-hakîm al- 'ârif) l'intention du verset coranique LVII, 23 : «Il en est ainsi afin que vous ne soyez pas désespérés en perdant ce qui vous échappe et ne vous n'exultiez pas de ce qui vous a été donné » ${ }^{45}$, ce qui souligne en creux que le sage antique vivait, pensait et agissait déjà conformément à la Loi révélée de l'islam.

Certaines maximes énigmatiques attribuées à Pythagore, probablement forgées en milieu monothéiste, donnent lieu à d'importants commentaires. Ainsi : «Qui aime Dieu agit par amour pour Lui ; qui agit par amour pour Lui se rapproche de Lui ; qui se rapproche de Lui est sauvé et victorieux ». Ashkevarî en trouve la confirmation dans un hadîth du sixième imâm : «N'aime pas Dieu celui qui Lui désobéit »; et dans le verset coranique : «Dis : "Suivez-moi, si vous aimez Dieu ; Dieu vous aimera"... » (III, 31) ${ }^{46}$. Le philosophe shî‘ite a le souci d'établir la symphônia, l'«accord » harmonique entre les dires des sages anciens et les paroles révélées - au Prophète et/ou à l'Imâm -, les unes et les autres faisant autorité, ne pouvant se contredire mais seulement se

\footnotetext{
${ }^{43}$ Ashkevarî, Mahbûb, p. 215-216. Cf. Porphyre, Vie de Pythagore, § 28-29, 33 et 35, p. 49, 51 et 52 ; Diogène Laërce, Vies et doctrines, VIII, 10, p. 949.

44 Porphyre, Vie de Pythagore, § 35, p. 52. Parallèles dans Diogène Laërce, Vies et doctrines, VIII, 23, p. 960 ; Jamblique, Vie de Pythagore, § 196, p. 106.

45 Ashkevarî, Maḥbûb, p. 216.

${ }^{46}$ Ashkevarî, Maḥbûb, p. 218. Le ḥadîth imâmite est tiré d'une source classique : al-Shaykh al-Ṣadûq (m. 381/991), Amâlî al-Ṣadûq, éd. Ḥâmid al-A'lamî, Beyrouth, Mu’assasat al-A'lamî li-l-maṭbû‘ât, 1430/2009, p. 353 , § 3.
} 
confirmer mutuellement ${ }^{47}$. Suit un long développement inspiré d'Ibn 'Arabî sur l'amour et ses trois formes naturelle, spirituelle et divine ${ }^{48}$. L'amour divin est l'amour réciproque de Dieu et de Son fidèle, conformément au verset coranique V, 54 : «Dieu fera bientôt venir des hommes ; Il les aimera, et eux aussi L'aimeront ». L'amour de Dieu pour Sa créature est une expression de Sa Toute-Puissance ; l'amour de Sa créature pour Lui est un mouvement vers sa perfection à travers l'unification (ittihâad) des caractères de l'amant et de l'aimé. Cet amour a pour concomitants l'espérance, la crainte, le désir, la familiarité (uns), l'épanchement (inbisât), la remise confiante (tawakkul), la satisfaction (riḍ̂a) et la soumission volontaire (taslîm) - des vertus exaltées par l'éthique tant soufie que shî‘ite. Ashkevarî conclut que «l'homme parfait (al-insân al-kâmil) est un amant et un parfait savant de l'amour et de ses concomitants, de l'aimé et de ses concomitants, des raisons pour lesquelles il est amant, des raisons pour lesquelles l'aimé est aimé, synthétiquement et analytiquement. Il est donc le plus ardent en amour. Dieu dit : «Ceux qui croient sont les plus ardents en l'amour de Dieu » (II, 165) $)^{49}$. Par ce tissage de citations et de réflexions personnelles, Ashkevarî ainsi apparente l'éthique pythagoricienne de la philia, dont il n'a reçu qu'un écho, à la mystique soufie de l'amour (maḩabba, ‘ishq), qui lui est familière, pour aboutir à la notion d'Homme parfait, dont l'expression est empruntée à Ibn 'Arabî mais dont le contenu plonge également ses racines dans l'ésotérisme shî‘ite et la philosophie antique ${ }^{50}$.

Autre recommandation attribuée à Pythagore, manifestement apocryphe : "Sois sûr que le fondement de la crainte de Dieu est Sa Miséricorde ». Ashkevarî éclaire cette formule énigmatique par deux paroles attribuées au premier imâm : «Ô homme, quand tu vois ton Seigneur te poursuivre de Ses bienfaits tandis que tu Lui désobéis, méfie-toi de Lui !»; «Méfiance, méfiance! Dieu a couvert [la faute] comme s'Il avait pardonné ${ }^{51}$. C'est là le thème, particulièrement développé par les mystiques soufis, du stratagème de Dieu (istidrâj) mettant le

\footnotetext{
${ }^{47}$ Sur ce principe de la symphônia, voir les remarques de A. Lecerf dans Hiéroclès, Commentaire, Introduction, p. 3031.

${ }^{48}$ Ibn 'Arabî, al-Futûhât al-makkiyya, éd. Maktab al-buhûth wa-l-dirâsât, Beyrouth, Dâr al-fikr, 1431-32/2010, III, p. 596 sq. ; trad. fr. Maurice Gloton, Traité de l'amour, Paris, Albin Michel, 1986, p. 66 ; H. Corbin, L'imagination créatrice, p. 166.

${ }^{49}$ Ashkevarî, Mahbûb, p. 219-220.

${ }^{50}$ Voir Pierre Lory et Mathieu Terrier, «al-Insân al-kâmil : 1'Homme parfait dans la culture arabe classique », Encyclopédie de l'humanisme méditerranéen, éd. Houari Touati, Leyde, Brill, 2017, URL : http://encyclopediehumanisme.com/?Al-insan-al-kamil-248.

51 'Alî b. Abî Ṭâlib (attribué à), Nahj al-balâgha, éd. Muḥammad 'Abdû et Ḥusayn al-A'lamî, Beyrouth, Mu'assasat al-a'lamî li-1-mațbû‘ât, 1413/1993, § 24 et 29, p. 631.
} 
croyant à l'épreuve en lui prodiguant tout le bien possible ${ }^{52}$. Ashkevarî veut ici faire entendre que la même mise en garde contre la même tentation fut donnée par 'Alî, l'Imâm ou le guide divin des shî‘ites, et par Pythagore, le sage divin et l'imâm des philosophes.

Pythagore se voit aussi attribuer l'assimilation platonicienne du corps et du tombeau (sômasêma) avec la maxime : "Celui dont l'âme ne domine pas le corps, son corps est le tombeau de son âme ${ }^{53}$. Ashkevarî en propose une interprétation d'esprit néoplatonicien typique de la philosophie islamique gnostique : «Il voulait peut-être signifier que quand l'âme cesse de dominer le corps et ses désirs corporels corrupteurs, ceci entraîne sa mort à la vie intellective (al-hayât al'aqlâniyya). Et quand l'âme meurt de son immersion dans le monde de la nature, son corps devient son tombeau $»^{54}$.

D’autres sentences attribuées à Pythagore et citées par Ashkevarî développent le thème, cher aux soufis, de l'intériorisation constante de la crainte de Dieu.

La multiplication des discours sur Dieu - exalté soit-Il - est le signe de l'impuissance de l'homme à Le connaître. Si à chaque fois que te vient à l'esprit quelque affaire du corps ou de l'âme, tu penses que Dieu est le témoin direct de toutes les actions, opérations et réflexions, tu rougiras aussitôt de honte devant Celui qui ne manque de rien voir. De même si tu places toute ta confiance en Dieu.

L'homme sage craignant Dieu est connu de Dieu, c'est pourquoi il est sans regret quand il est inconnu de tout le monde.

La dernière rejoint un authentique topos de la philosophie grecque, une sagesse polythéiste traduite en langage monothéiste :

Les hommes du commun croient que le Créateur Très-Haut se trouve seulement dans les temples (hayâkil), aussi est-ce là qu'ils veillent à bien agir. De même, celui qui sait que Dieu est en tout lieu doit agir en tout lieu comme les hommes du commun agissent dans les temples ${ }^{55}$.

\section{Le sage martyr}

Dans l'histoire de la sagesse d'Ashkevarî, Pythagore apparaît non seulement comme un sage auto-déifié, initié à la « niche aux lumières de la prophétie », et un maître d'éthique monothéiste,

\footnotetext{
${ }^{52}$ Ashkevarî, Mahbûb, p. 221. Voir sur ce thème Riyadh Atlagh, « Tentation », Dictionnaire du Coran, p. 863-867.

${ }_{53}^{53}$ Platon, Cratyle, 400c-d ; Id., Phèdre, 250c.

${ }^{54}$ Ashkevarî, Mahbûb, p. 221-222.

${ }^{55}$ Ibid., p. 222-223. La dernière sentence rappelle « Tout est plein de dieux », attribué à Thalès d'après Platon, Lois, 899b9, et « Il y a des dieux aussi dans la cuisine », attribué à Héraclite par Aristote, Parties des animaux, 645a.
} 
mais aussi comme un martyr de la cause philosophique et religieuse. Le récit de sa mort rapporté par le philosophe shî‘ite, résumé dans les lignes suivantes, provient de la tradition biodoxographique arabe dérivée de Porphyre. Comme Pythagore, avant d'entreprendre un voyage, avait réuni ses amis dans la maison d'un certain Milon ${ }^{56}$, les pythagoriciens furent attaqués par les partisans de Cylon, un riche aristocrate de Crotone. Quelque temps auparavant, Pythagore l'avait congédié de son assemblée en lui recommandant de purifier son âme ; offusqué par cette leçon, Cylon s'était employé à calomnier Pythagore, à l'accuser d'impiété et à appeler au meurtre contre lui. Ce jour-là, quarante pythagoriciens furent tués, et de ceux qui prirent la fuite avec le maître, nombre subirent le même sort. Pythagore et ses partisans rescapés se rendirent à Caulonia puis à Locres, d'où les chefs de la cité le prièrent de partir à cause des diffamations répandues contre lui. À Métaponte, comme de nouvelles émeutes éclataient, Pythagore se réfugia avec les siens dans le temple des Muses où ils demeurèrent quarante jours sans manger. Enfin, leurs ennemis mirent le feu au temple ; les amis de Pythagore firent cercle autour de lui pour le protéger des flammes et il mourut étouffé avant qu'ils ne soient brûlés ${ }^{57}$.

Ce récit, assez fidèle à celui validé par Porphyre, sert idéalement l'historiosophie d'Ashkevarî, sa conception shî'ite d'une histoire tragique et téléologique de la vérité. La persécution de Pythagore, son exode forcé, le drame final unissant le maître et ses disciples dans la mort violente et injuste, résonnent d'autant plus fortement avec l'histoire des imâms shî‘ites qui, selon la tradition, ont tous connu des sorts tragiques, que les pythagoriciens sont désignés comme les «shî'ites » de Pythagore (shî‘a Fîthâghûris). Si le terme a originellement le sens générique d'« adeptes » ou de « partisans » et se trouve déjà dans les sources doxographiques (Ḥunayn ?) ${ }^{58}$, il prend bien ici le sens technique de ceux qui souffrent et meurent pour leur guide divin, autrement

\footnotetext{
${ }^{56}$ Les transcriptions arabes des patronymes et toponymes sont altérées mais reconnaissables.

${ }^{57}$ Ashkevarî, Mahbûub, p. 216-217. Cf. Porphyre, Vie de Pythagore, § 54-57, p. $62-64$; Jamblique, Vie de Pythagore, $\S 248-249$, p. 132-133 ; Diogène Laërce, Vies et doctrines, VIII, 39-40.

${ }^{58}$ L'expression shî 'a Fîthâghûris se trouve déjà chez Ḥunayn b. Isḥâq, Âdâb al-falâsifa, p. 39 ; al-Fârâbî, Kitâb fì mâ yanbaghî an yuqaddama qabla ta 'allum al-falsafa, dans Alfârâbî̀'s Philosophische Abhandlungen, éd. Friedrich Dietereci, Leyde, Brill, 1890-92 [réimpr. Hildesheim, Olms, 2011], repris dans la série Publications of the Institute for the History of Arabic-Islamic Science, éd. Fuat Sezgin, Frankfurt am Main, Institute for the History of ArabicIslamic Science at the Johann Wolfgang Goethe University, 1999, vol. 12, p. 49-55, ici p. 49-50 ; Șâ‘id al-Andalusî, Tabaqât al-umam, p. 32 (trad. fr. R. Blachère, p. 75). Les sceptiques sont également appelés shî'a Fûrûn ("les partisans de Pyrrhon ») et les épicuriens shî'a Ifighhûris (« les partisans d’Épicure ») dans ces sources, mais n’auront pas la même postérité.
} 
dit des shî'ites imâmites. Ce récit doloriste, fidèle à l'hagiographie pythagoricienne d'un Jamblique $^{59}$, fait donc pleinement sens pour la conscience religieuse shî́ite.

Plus encore, la suite de notices qu'Ashkevarî consacre à Empédocle, Pythagore et Socrate illustre la destinée tragique du sage initié à la niche aux lumières prophétiques - à l'instar de l'imâm lui-même - : le premier, Empédocle, banni en raison de ses vues sur la résurrection (al$\left.m a a^{\prime a} d\right)$; le deuxième, Pythagore, assassiné à cause de son appel à une vie philosophique ; le troisième, Socrate, mis à mort par le pouvoir pour s'être opposé à l'idolâtrie et avoir professé un strict monothéisme ${ }^{60}$. Avant comme après la mission du prophète Muhammad, la sagesse dut se voiler et souffrir mille épreuves en attendant sa manifestation finale, laquelle ne viendra qu'avec la parousie du douzième imâm.

\section{Pythagore, maitre de theologie monotheiste}

\section{L'Un-Dieu et son ombre}

Passons au Pythagore maître de philosophie et de théologie monothéiste. Son pedigree, ses exploits, son enseignement et sa mort nous ont préparés à l'entendre. Mîr Dâmâd en est le principal porte-voix, qui reprend à son compte l'arithmologie pythagoricienne en lui conférant une portée théologique, cosmologique et anthropologique considérable.

Dans son Raffermissement de la foi (Taqwîm al-îmân), il entend proposer une conception philosophique rigoureuse du tawhî̀d, l'attestation de l'unicité divine, premier article de foi de l'islam. Il identifie d'emblée les concepts d'unité (waḥda) et d'être (wujûd), faisant de la théologie une hénologie, ou science de l'Un, autant qu'une ontologie, ou science de l'Être. L'Unité absolue est l'être pur de Dieu, dont émanent les intelligences sans le diviser. Dieu est aussi conçu, à la suite d'Avicenne, comme l'être nécessaire par soi (wâjib al-wujûd bi-dhâtihi) et toutes les choses créées comme des êtres possibles par essence et nécessitées par Dieu. Mîr Dâmâd s’attache donc à faire

\footnotetext{
${ }^{59}$ Constantinos Macris, « Le pythagorisme érigé en hairesis ou comment (re)construire une identité philosophique. Remarques sur un aspect méconnu du projet pythagoricien de Jamblique », Entre lignes de partage et territoires de passage. Les identités religieuses dans les mondes grec et romain, dir. Nicole Belayche et Simon C. Mimouni, Paris - Louvain - Walpole, Peeters, 2009, p. 139-168, surtout p. 164.

${ }^{60}$ Ashkevarî, Maḥbûb, p. 206, 216-217, 238-242 ; M. Terrier, Histoire de la sagesse, p. 364, 382-383, $423-427$.
} 
le départ entre l'Un-Dieu et l'un numérique : « l'Un véritable, créateur des quiddités et des ipséités, est d'une essence trop sublime pour que son unité véritable soit une unité numérique ${ }^{61}$. Cette dernière est ce par quoi se produit la multiplicité ; elle subsiste dans un lieu extérieur à sa quiddité, lui advenant par accident; elle est d'essence intelligible et connue. L'unité véritable, elle, est subsistante par elle-même, elle est sa propre unité et non celle d'une autre chose ; elle est « l'être subsistant par soi, étant sa propre individuation, sa propre unité, régnant sur les puissances intellectives et les intelligences immatérielles ${ }^{62}$. Elle ne peut être réitérée ni dans les essences concrètes (fí l-a 'yân), ni dans l'esprit in abstracto. C'est pourquoi elle échappe à l'intelligence comme à la perception sensible, étant «le principe d'émanation de l'unité qui est objet de connaissance et de la multiplicité subsistant dans l'être par cette unité » ${ }^{63}$. En somme, «l'unité de nécessité est l'être pur et simple », « imparticipable dans son être, dans sa réalité, dans la perfection de son être, dans la gloire de son essence et dans le rang de sa splendeur ${ }^{64}$, quand l'unité numérique est «l'unité accidentelle de quelque ipséité possible (...), une unification voilée et circonscrite de ce qu'ombrage l'unité véritable ${ }^{65}$. L'affirmation selon laquelle l'unité numérique n'est que l'ombre de l'unité véritable de Dieu revient comme un leitmotiv dans l'œuvre de Mîr Dâmâd ${ }^{66}$. Cette conception s'appuie sur une référence à Pythagore :

La vérité ferme a été dite par Pythagore et répétée par les pythagoriciens. Ils disaient parfois que l'unité est [de deux sortes]. La première est l'unité subsistante dans l'être par essence (qâ 'ima bi-l-dhât), non dérivée d'un autre, à laquelle nulle multiplicité ne correspond, dont nulle multiplicité ne se compose. Elle est l'unité du Principe véritable premier, l'unité de l'enveloppement de toutes choses, car par l'unité de Son essence « [Dieu] enveloppe toute chose» (Coran, XL1, 54). La seconde est l'unité subsistante par l'autre et dérivée de l'autre ; elle est le principe de la composition de la multiplicité et la multiplicité lui fait face ; puis les nombres se composent par elle. Elle est l'unité des choses créées.

Parfois, ils disent que l'unité dans l'absolu est de [quatre sortes] : une unité avant l'éternité (dahr), une unité avec l'éternité, une unité après l'éternité et avant le temps (zamân), une unité avec le temps. L'unité avant l'éternité est l'unité du Créateur; l'unité avec l'éternité et avant le temps est l'unité de

\footnotetext{
${ }^{61}$ Mîr Dâmâd, Taqwîm al-îmân, éd. 'Alî Awjabî, Téhéran, Mirâth-e maktûb, 1382 h.s./2003, p. 281. Cette distinction était déjà de rigueur dans la philosophie néopythagoricienne de l'Antiquité tardive : voir André Jean Festugière, « L’Un transcendant aux nombres », Id., La Révélation d'Hermès Trismégiste, t. IV : Le Dieu inconnu et la gnose, Paris, J. Gabalda, 1954, p. 18-31 ; Joel Kalvesmaki, « One versus One : The Differentiation Between hen and Monad in Hellenistic and Late Antique Philosophy », Id., The Theology of Arithmetic. Number Symbolism in Platonism and Early Christianity, Washington, Center for Hellenic Studies, 2013, p. 175-182.

${ }^{62}$ Mîr Dâmâd, Taqwîm, p. 282.

${ }^{63}$ Ibid., p. 284.

${ }^{64}$ Ibid., p. 285.

${ }^{65}$ Ibid., p. 283.

${ }^{66}$ Par exemple Jadhawât, p. 165, 170, 180 et 215 ; Taqwîm, p. 280-281 ; et référence infra, n. 75.
} 
l'Intellect premier ; l'unité après l'éternité et avant le temps est l'unité de l'Âme ; l'unité avec le temps est l'unité des éléments et des composés ${ }^{67}$.

Cette dernière distinction rejoint celle opérée ailleurs par Mîr Dâmâd entre trois niveaux : a) une éternité absolue appelée sarmad : l'éternité absolument imparticipable de l'Un divin, de l'Un au-delà de l'Être, correspondant à la pure unicité divine (tawhîd) ; b) une éternité relative ou un anté-temps appelé dahr : l'éternité participée de l'Intellect, correspondant à l'unité participée dans l'être et la multiplicité ; c) le temps (zamân), mesure du mouvement dans le monde naturel selon la définition aristotélicienne. Un schéma qui pourrait trouver son origine chez Proclus avec substitution de l'Un à l'Être ${ }^{68}$. C'est sur la base de cette tripartition ontologique que notre philosophe conçoit l'advenue du monde comme ni temporelle ni absolument éternelle, mais « antétemporelle » (dahrî), échappant ainsi à l'antinomie de l'éternité ou de la nouveauté du monde ${ }^{69}$.

Plus loin, Mîr Dâmâd distingue, au sein de l'unité par accident, entre celle qui est principe du nombre et n'entre pas dans le nombre, et celle qui est principe du nombre et entre dans tous les nombres. La première est celle de l'Intellect agent, « car celui-ci n'entre pas dans le nombre et le nombré $»^{70}$. Au sujet de la production du multiple à partir du second type d'unité par accident, il conclut que «les plus vénérés des métaphysiciens [litt. « divins » (ilâhiyyîn)] parmi les sages grecs » - formulation qui comprend sans doute Pythagore - « ont mentionné qu'à mesure que les choses instaurées et causées se multiplient, que leur composition augmente et redouble, la simplicité et l'unité du Principe premier, loué soit Son nom, devient plus intense et plus puissante $»^{71}$. Chez les anciens Grecs, notre philosophe découvre ainsi une synthèse entre la pure unicité de Dieu et la multiplicité de la création, dont il sera encore question plus loin ${ }^{72}$.

C'est en récupérant la même matière doxographique que Mullâ Șadrâ établit la congruence de quatre voies d'appréhension du Vrai : celle des pythagoriciens, celle des péripatéticiens (comme Avicenne), celle des «illuministes » (ishrâqiyyûn) et celle des soufis cultivant l'amour mystique :

\footnotetext{
${ }^{67}$ Mîr Dâmâd, Jadhawât, p. 46-47 et 177 ; Taqwîm, p. 285-286; d'après Shahrastânî, Milal, II, p. 79 (Religions et sectes, II, p. 202). Voir sur ce passage Anna Izdebska, « The Pythagorean Metaphysics of Numbers in the Works of the Ikhwān al-Șafā' and al-Shahrastāni », Pythagorean Knowledge from the Ancient to the Modern World, éd. A.-B. Renger et A. Stavru, p. 361-374, ici p. 368-369.

${ }^{68}$ Proclus, The Elements of theology, éd. et trad. angl. Eric R. Dodds, Oxford, Clarendon, 1963 [réimpr. 2004], prop. 88 , p. $80-81$, et prop. 106 , p. $94-95$.

${ }^{69}$ Mathieu Terrier, «De l'éternité ou de la nouveauté du monde. Parcours d'un problème philosophique d'Athènes à Ispahan », Journal asiatique 299.2, 2011, p. 369-421, ici p. 401-411.

${ }^{70}$ Mîr Dâmâd, Jadhawât, p. 47.

${ }^{71}$ Ibid., p. 48-49.

${ }^{72}$ Voir infra, p. 20-25.
} 
Le sage parfait Pythagore et ses compagnons s'employèrent aux recherches sur l'arithmétique, les propriétés des nombres, leurs rangs, leur mode d'engendrement à partir de l'un et leur retour à lui, car tous partent de l'un et retournent à lui. Cette voie les a conduits à la connaissance du Démiurge Innovateur (al-șâni ' al-badî'), de Ses attributs, de Ses effets et de Ses actions; elle les a amenés à la découverte des états de Son essence, soit la contemplation des états de l'unité, de l'Un réellement véritable, de la relation de la multiplicité et du nombre avec lui. De même, la voie de certains sages dans la connaissance du Réel divin, de Ses attributs et de Ses actes, est la contemplation des états de l'existence (al-wujûd) et de l'existant en tant qu'existant (al-mawjûd bi-mâ huwa mawjûd). Toutes deux ne forment qu'une seule voie, car l'existence et l'unité sont unies en réalité et par essence (...). Il en va de même pour la voie de la lumière qui est celle des Illuministes et la voie de l'amour d'un certain groupe de soufis, lesquelles remontent aussi, par approfondissement, à la voie de l'existence ${ }^{73}$.

Enfin, Ashkevarî, toujours à l'affût de la symphônia entre la sagesse antique et la Science révélée, confirme la parole de Pythagore : «Le Créateur est Un, mais pas comme les unités [numériques], car Il n'entre pas dans le nombre », par un ḩadîth du premier imâm expliquant les sens autorisés et les sens illicites de la formule «Dieu est un » (Coran, CXII, 1) ${ }^{74}$, puis par un tissage de citations traditionnelles dont les interprétations sont empruntées à Mîr Dâmâd :

Nous disons que dans cette parole de la Révélation : «Il n'y a pas d'entretien à trois où Il ne soit le quatrième, ni à cinq où Il ne soit le sixième » (LVIII, 7), il ne faut pas s'imaginer qu'il est question du quatrième des trois et du sixième des cinq selon le nombre ; mais seulement de ce que l'école de la gnose (madhhab al-'irfân) a jugé licite dans son commentaire, à savoir que Dieu est le quatrième de tout trois et le sixième de tout cinq par l'Enveloppement et l'Être-avec enveloppant, comme il apparaît clairement dans Sa parole explicite : "... Qu'ils soient moins ou plus nombreux, Il est avec eux là où ils se trouvent » (LVIII, 7). Et ce qui se trouve dans le saint Feuillet du Prosterné (al-Ṣahîffat al-sajjâdiyya) [scil. le psautier du quatrième imâm al-Sajjâd (m. ca 95/714)] : «À Toi, mon Dieu, est l'unicité du nombre ! ». Sa signification est conforme à ce qu'a expliqué l'un de nos éminents savants [scil. Mîr Dâmâd], à savoir que l'unité numérique est une ombre de Son unité réelle, pure et subsistante, un effet de Son effectivité absolue et de Son activité instauratrice. Ainsi l'usage du «à»dans la parole [de l’imâm] : «à Toi », est le même que dans la parole [de Dieu] : « À Lui ce qui est dans les cieux et sur la terre » $(\text { Coran, IV, 171) })^{75}$.

Chez Mîr Dâmâd, l' « Être-avec enveloppant » (al-ma 'iyya al-ihâtiyya) désigne donc la manière dont Dieu est « avec» $\left(m a^{\prime} a\right)$ les créatures en les comprenant et en les transcendant tout à la fois. Cette relation qui lie l'Un absolu et imparticipable au multiple participant de l'unité numérique, le radicalement intemporel au temporel, n'est elle-même ni temporelle ni absolument éternelle mais

\footnotetext{
${ }^{73}$ Mullâ Șadrâ, Mafâtih al-ghayb, 2 vol., éd. N. Ḥabîbî, Téhéran, Intishârât-e bonyâd-e hịikmat-e islâmî-ye Șadrâ, 1386 h.s./2007-2008, I, p. 404-405.

${ }^{74}$ Ashkevarî, Mahbûb, p. 224-225 ; M. Terrier, Histoire de la sagesse, p. 392-393.

${ }^{75}$ Ashkevarî, Mahbûbb, p. 225. Sources : jusqu'au v. LVIII, 7, Mîr Dâmâd, Taqwîm, p. 289 ; par la suite, Mîr Dâmâd, Sharh al-șahîfa al-sajjâdiyya al-kâmila, éd. Muḥammad Rajâ'î, Ispahan, Bahâr-e qulûb, 1422/2001-02, p. 273.
} 
« anté-temporelle » (dahrî). L'unité numérique se situe à ce niveau du dahr, comme intermédiaire entre l'Unité absolue de Dieu, dont elle est l'ombre, et la multiplicité numérique dont elle est le principe.

\section{Deus absconditus}

Avec une telle conception de l'unicité divine, il n'est pas étonnant que Pythagore se soit vu attribuer, dans les sources doxographiques arabes, une théologie apophatique, analogue à celle des mu'tazilites rationalistes des III-IV $/ \mathrm{IX}-\mathrm{X}^{\mathrm{e}}$ siècles, également soutenue par les imâms shî'ites dans nombre de hadîths qui leur sont attribués ${ }^{76}$. Pour Mîr Dâmâd, « le fond (kunh) de l'unité véritable [de Dieu] est hors de la capacité de l'intelligence et du champ de la perception ${ }^{77}$. Un philosophème attribué à Pythagore confirme cette idée en reprenant la distinction, classique dans la théologie islamique, entre l'essence de Dieu, Ses attributs et Ses actions :

[Le Créateur] n'est saisi ni du côté de l'Intellect, ni du côté de l'Âme ; la réflexion intellectuelle est incapable de Le saisir et le langage de l'âme est incapable de Le décrire. Il est au-dessus des attributs spirituels, insaisissable dans Son essence mais saisissable seulement à travers Ses effets, Ses productions et Ses actions. [...] Chacun Le décrit du point de vue de sa propre essence et Le sanctifie à partir des propriétés de ses propres attributs $»^{78}$.

Ashkevarî rapproche ce propos d'un hadîth du cinquième imâm al-Bâqir (m. ca 114/732) commenté par le philosophe Jalâl al-Dîn al-Dawânî (m. 908/1502-03) :

«Toutes les fois que vous Le discernez par vos imaginations dans Ses significations intelligibles les plus subtiles, [Dieu] devient un être créé et produit tout comme vous, rapporté à vous-mêmes. Les petites fourmis s'imaginent peut-être que Dieu le Très-Haut a deux antennes, car telle est leur perfection, et elles s'imagineraient l'absence [d'antennes] comme un défaut [...]. La condition des hommes intelligents, dans ce qu'ils attribuent à Dieu le Très-Haut, est identique ${ }^{79}$. » Quelque illustre moderne déclara : «C'est une parole (...) procédant de la source même de la réalisation spirituelle et de la réflexion subtile. Son secret, c'est que l'obligation porte seulement sur la connaissance de Dieu qui est à la mesure de la capacité et de l'aptitude. [Les créatures] ne sont obligées de Le connaître que par les attributs qui leur sont familiers et qu'elles observent en elles-mêmes, avec la négation des défauts contraires entrainés par cette attribution à elles-mêmes. Comme l'homme est nécessité [à être] par un

\footnotetext{
${ }^{76}$ Ignaz Goldziher, Le dogme et la loi dans l'Islam, trad. fr. Félix Arin, $2^{\mathrm{e}}$ éd., Paris - Tel-Aviv, Geuthner - L'éclat, $2005\left[1920^{1}\right]$, p. 88-95; Louis Gardet et George Anawati, Introduction à la théologie musulmane : essai de théologie comparée, Paris, Vrin, 1948 [réimpr. 1981], p. 47-49 et 56-58.

${ }^{77}$ Mîr Dâmâd, Taqwîm, p. 285.

${ }^{78}$ Mîr Dâmâd, Jadhawât, p. 46 ; Ashkevarî, Mahbûb, p. 227 ; U. Rudolph, Pseudo-Ammonios, p. 51.

${ }^{79}$ Sur l'analogie avec un fameux fragment de Xénophane, voir M. Terrier, Histoire de la sagesse, p. 415-416.
} 
autre que lui, qu'il est savant, puissant, vivant, parlant, entendant et voyant, il a l'obligation de croire que ces attributs se trouvent dans la Réalité du Très-Haut, avec la négation des défauts contraires engendrés par leur attribution à l'homme. [Il est donc obligé] de croire que le Très-Haut est nécessaire par Sa propre essence, non par un autre, qu'Il est savant de toutes choses connues, puissant sur tous les possibles, et de même pour tous les attributs. [Nul] n'a donc l'obligation de croire en un attribut du TrèsHaut dont il ne trouverait absolument aucun exemple en nous, car s'il en avait l'obligation, il ne lui serait pas possible de l'intelliger en vérité. C'est l'une des significations de la parole de notre maître, le Prince des croyants [scil. l'imâm 'Alî] - les prières de Dieu soient sur lui - : «Qui se connaît lui-même connaît son Seigneur $»^{80}$.

La théologie renfermée dans la formule de Pythagore s'avère être identique à la théologie imâmite et mu'tazilite. Ashkevarî conclut sur un paradoxe : Dieu ne Se manifeste en aucun lieu de manifestation (maẓhar) sans se dissimuler par là-même ${ }^{81}$. L'apophatisme, qui apparaît chez Pythagore lui-même comme une conséquence rigoureuse du tawhîd, l'attestation de l'unicité de Dieu, est ainsi articulé au théophanisme, corollaire d'une certaine conception de la multiplicité et de la création également attribuée à Pythagore.

\section{L'Un et le multiple}

Dans ses Tisons ardents et temps fixés (Jadhawât wa mawâqît), Mîr Dâmâd repense à nouveaux frais l'arithmologie pythagoricienne pour déduire de l'hénologie une herméneutique du multiple à partir de la dyade :

Il est établi par la science de l'arithmétique, comme l'ont affirmé unanimement Nicomaque, Pythagore et Platon, les professeurs de l'art, les finisseurs de la démiurgie et les imâms de la sagesse, que l'un [...] n'appartient pas à l'espèce du nombre ; mais en tant qu'il engendre toutes les espèces du nombre, ils le font rentrer dans le nombre. [...] Certains pythagoriciens, et Pythagore lui-même dans certains de ses propos, considèrent le deux comme le pair mais non comme un nombre. Ils tiennent alors le trois pour le premier nombre impair et le premier des nombres, et le quatre pour le premier des nombres pairs. Suivant cette différence, la plupart ont vu dans le deux l'hymen (nikâh) qui parcourt toutes les particules ${ }^{82}$, affirmant que l'engendrement des enfants de l'existence provient du mariage (izdivâj) de la puissance active de l'agent avec la puissance passive du patient. Pour certains, c'est le

\footnotetext{
${ }^{80}$ Ashkevarî, Mahbûb, p. 227-228. Tout le passage est emprunté à Jalâl al-Dîn al-Dawânî, Risâlat ithbât al-wâjib aljadîda, dans Id., Sab 'a rasâ'il, éd. Aḥmad Tuysirkânî, Téhéran, Mirâth-e maktûb, 1381 h.s./2002, p. 158-159. Sur ce philosophe, voir Mathieu Terrier, «Dawānī, Jalāl al-Dīn al- », Encyclopedia of Medieval Philosophy, éd. Henrik Lagerlund, Dordrecht, Springer, 2019, online, à paraître. Le dernier hadîth cité est également attribué au Prophète, à qui la formule eulogique employée ici pour l'imâm est communément réservée ; il s'agit là d'une marque nettement shî‘ite.

${ }^{81}$ Ashkevarî, Mahbûb, p. 228.

${ }^{82}$ L'expression vient du titre d'un ouvrage d'Ibn 'Arabî : Kitâb al-nikâh al-sârî fì jamî̀ al-dharârî. Voir Osman Yahya, Histoire et classification de l'œuvre d'Ibn 'Arabî : étude critique, Damas, Institut français de Damas, 1964, p. 412.
} 
trois, comprenant la puissance active, la puissance passive et le mariage entre elles, qui est le fondement de la naissance des êtres engendrés ${ }^{83}$.

L'introduction de ce passage présente encore Pythagore, avec Platon et Nicomaque ${ }^{84}$, sous des titres hautement signifiants qui pourraient leur venir de l'alchimie arabe ${ }^{85}$. Pythagore apparaît ainsi à l'origine d'une autre conception de l'amour comme principe cosmique, apparemment inspirée d'Ibn 'Arabî.

Mîr Dâmâd rappelle l'origine empirique et mystique de cette théorie des nombres pour affirmer toute sa portée cosmologique et métaphysique :

Les plus grands sages divins et savants seigneuriaux (a âżim-e hokamâ-ye elâhiyîn va âfâkhim-e 'olamâ-ye rabbâniyîn), eux qui perçoivent les nourritures des réalités véritables et des connaissances subtiles par le sens gustatif de la faculté sainte et de l'intuition spirituelle (beh dhâyiqeh-ye qovvat-e qodsî va dhawq-e dhayeqeh-ye hadsî), s'accordent à dire que les rangs des mondes générés correspondent à ceux du monde du nombre, que les relations entre les êtres générés correspondent à des relations numériques, que les compositions des relations et les combinaisons des propriétés du monde numérique - qui sont les ombres des mariages contractés par désir, les traces des étreintes des lumières du monde intelligible - sont les miroirs et les mesures des réalités des ipséités générées (marâ'î va ma'âŷtr-e haqâyeq-e hoviyyât-e kawn ${ }^{86}$.

Le sens du goût (dhawq, dhâ'iqa), dans le soufisme et la gnose philosophique ( 'irfân), sert communément à désigner une intuition spirituelle directe supérieure à la connaissance représentative par abstraction. De manière plus allusive que Mullâ Șadrâ, Mîr Dâmâd évoque ainsi la confluence des voies pythagoricienne - celle du nombre -, soufie - celle de l'amour - et illuministe - celle de la lumière.

La connaissance des propriétés et des rangs du monde numérique, ajoute le philosophe shî‘ite, confère la connaissance «des mesures et des modalités des événements passés et présents », cette connaissance que possédait le premier imâm, désigné comme « la porte de la cité

\footnotetext{
${ }^{83}$ Mîr Dâmâd, Jadhawât, p. 105-106.

${ }^{84}$ Il s'agit en principe de Nicomaque de Gérase (II siècle), néopythagoricien auteur de l'Introduction arithmétique qui était bien connue dans le monde arabe ; voir Gad Freudenthal, "L'Introduction arithmétique de Nicomaque de Gérase dans les traditions syriaque, arabe et hébraïque », Dictionnaire des philosophes antiques, dir. Richard Goulet, t. IV, Paris, CNRS Éditions, 2005, p. 690-694. Mais Ashkevarî dit aussi de Nicomaque père d'Aristote qu'il était un disciple de Pythagore; voir Mahbûb, p. 274. Il ne serait donc pas à exclure que les deux personnages se confondent pour nos auteurs.

${ }^{85}$ Voir Pierre Lory, Alchimie et mystique en terre d'Islam, Paris, Gallimard, $2003^{2}$ [1989'] , p. 58-59 : des ouvrages d'alchimie étaient attribués à Pythagore et Platon cependant que l'alchimie était fréquemment désignée par le terme de «philosophie».

${ }^{86}$ Mîr Dâmâd, Jadhawât, p. 119.
} 
de la science, la demeure de la cité de la sagesse, l'habitant de l'argile de la certitude, le natif de la $k a$ 'ba de l'islam, le Prince des croyants et le Seigneur des mandataires, 'Alî Ibn Abî Tâlib », et les imâms de sa descendance ${ }^{87}$. Mîr Dâmâd l'illustre par le récit suivant. Un jour, un juif mit 'Alî au défi de trouver un nombre n'ayant que des nombres entiers pour moitié, tiers, quart, cinquième, sixième, septième, huitième, neuvième et dixième. En réponse, 'Alî lui dit de multiplier le nombre de jours de la semaine par celui des jours du mois puis par le nombre des jours de l'année, ce qui donne d'après Mîr Dâmâd 7 fois 30 fois $360=75600$. Subjugué par l'imâm, le juif se convertit alors à l'islam ${ }^{88}$. Après le prodige physique d'ubiquité, c'est par le prodige intellectuel du calcul que 'Alî est rapproché de Pythagore. Tout se passe comme si l'imâm 'Alî parachevait la vocation religieuse du sage Pythagore en mettant l'arithmétique au service du plus parfait monothéisme, l'islam imâmite.

Enfin, Mîr Dâmâd attribue aux pythagoriciens, appelés ici «les familiers de Pythagore » (âl Fîthâghûris) - autre expression à connotation shî‘ite -, les principes de la science des lettres et des nombres, parente arabe de la gematria juive, dans laquelle il voit la clé de la correspondance entre la nature et la révélation :

Les familiers de Pythagore ont dit: «La condition des existants n'est connue que par le nombre et les compositions géométriques selon des relations numériques. C'est pourquoi les corps mobiles célestes possèdent des mouvements relatifs qui sont les plus nobles des mouvements et les plus subtiles des compositions. Les lettres séparées de la matière font partie des principes : le alif correspond à l'un, le $b \hat{a}^{\prime}$ au deux, et ainsi de suite. Les Lois révélées (sharấ' $i$ ) qui fixent la mesure des prières, des aumônes et des autres actions de culte, visent seulement à synchroniser ces rapports avec ces harmonies spirituelles ».

Dans le monde de la comparaison et de la représentation [scil. le monde sensible], les règnes du nombre et de la lettre sont au macranthrope (ensân-e kabîr) ce que l'entendement et l'imagination sont au micranthrope »(ensân-e șaghîr). La production de la forme dans l'entendement fait partie des principes de l'advenue de ce qui a une forme dans le monde extérieur ${ }^{89}$.

Nous reviendrons sur cette analogie, d'origine pythagoricienne, entre l'homme comme microcosme et le monde comme macranthrope ${ }^{90}$. Notre philosophe conclut ce passage en homologuant, au moyen d'une tradition sur la vie du huitième imâm, cette science des lettres et

\footnotetext{
${ }^{87}$ Ibid., p. 120. Tous ces titres désignant 'Alî sont classiques dans le shî‘isme.

${ }^{88}$ Ibid., p. 120-121.

${ }^{89}$ Ibid., p. 134-135.

${ }^{90}$ Voir infra, p. 25-26.
} 
des nombres à la science divinatoire contenue dans les livres secrets des imâms, connus des shî‘ites par leurs seuls titres al-Jâmi 'a (la Réunion) et al-Jafr (le Calcul) ${ }^{91}$.

Plus loin, Mîr Dâmâd attribue à Pythagore une autre conception de la procession du multiple ou du nombré ( $a l-m a$ 'd $\mathrm{u} d$ ) à partir de l'un, correspondant à la hiérarchie néoplatonicienne des hypostases :

[Pythagore] dit : «Le nombré ayant en lui de la dualité, qui est l'origine et le principe des nombrés, est l'Intellect. Il existe deux points de vue sur lui : en lui-même, en tant que son être est possible par soi ; selon son Instaurateur, en tant que son être est nécessaire par Lui. Le nombré ayant en lui de la triplicité est l'Âme, car aux deux points de vue précédents s'ajoute un troisième. Le nombré ayant en lui de la quaternité est la Nature, car aux trois points de vue précédents s'ajoute un quatrième. Là s'arrêtent les principes, puis commencent les composés. [...] En somme, la condition des étants n'est connue que par le nombre et les mesures premières. Le Créateur Très-Haut connaît tous les objets de connaissance sur le mode de l'enveloppement par les causes qui sont les nombres et les mesures $\gg^{92}$.

L'arithmologie pythagoricienne semble être ainsi la voie royale de la connaissance de la Science divine elle-même, celle-ci étant conçue comme «être-avec enveloppant » et « enveloppement de toutes choses », conformément au verset XL1, 54 : « La Science de Dieu n'enveloppe-t-elle pas toute chose ?».

Ashkevarî, pour sa part, expose l'arithmologie pythagoricienne d'après les Ikhwân al-ṣafâ $\left(\mathrm{IV}^{\mathrm{e}} / \mathrm{X}^{\mathrm{e}}\right.$ siècle), shî‘ites hétérodoxes connus pour revendiquer l'héritage de Pythagore ${ }^{93}$. On y retrouve la distinction entre l'Un-Dieu et l'un numérique et la traduction réciproque de l'ontologie en hénologie :

[Pythagore] dit: « Sache que le principe du nombre est l'un et que le nombre se compose à partir de l'un. L'un est la cause du nombre, tout comme le Créateur est la cause des étants. De même que l'un n'a ni partie, ni semblable, ni associé, le Créateur n'a ni partie, ni semblable, ni associé. De même que l'un donne son nom à tout nombre et à toute mesure, le Créateur a donné leur être à [tous] les étants et a nommé tout étant par le nom qui lui convient. De même que le nombre subsiste par la subsistance de l'un, les étants tirent leur subsistance et leur pérennité de la subsistance du Créateur. De même que le

\footnotetext{
${ }^{91}$ Mîr Dâmâd, Jadhawât, p. 135. Sur ces livres, voir M. A. Amir-Moezzi, Le Guide divin, p. 186-187.

${ }^{92}$ Mîr Dâmâd, Jadhawât, p. 178-179.

${ }_{93}$ Sur ce dossier, voir Yves Marquet, Les "Frères de la pureté », pythagoriciens de l'Islam. La marque du pythagorisme dans la rédaction des Épîtres des I $\underline{h} w a ̂ n$ al-Safầ', Paris, S.É.H.A./Edidit, 2006 ; Daniel De Smet, « Yves Marquet, les Ihwān al-ṣafā' et le pythagorisme », Journal asiatique 295, 2007, p. 491-500 ; Nader El-Bizri, " The Occult in Numbers: The Arithmology and Arithmetic of the Ikhwān al-Șafā' », The Occult Sciences in Pre-Modern Islamic Cultures, éd. N. El-Bizri et Eva Orthmann, Beyrouth, Orient-Institut / Würzburg: Ergon Verlag, 2018, p. 1740 ; Guillaume de Vaulx d'Arcy, Les épîtres des Frères en Pureté (Rasā'il Ihwāan aṣ-Șafā') : Mathématique et philosophie, Paris, Les Belles Lettres, 2019.
} 
nombre naît et augmente par la réitération de l'un, les étants naissent de l'effusion et de la libéralité universelle du Créateur... ${ }^{94}$.

L'analogie se poursuit: au deux, premier nombre né de la réitération de l'un, correspond l'Intellect premier comme premier étant émané de l'Être du Créateur ; au trois correspond l'Âme, subordonnée à l'Intellect; au quatre la Nature, subordonnée à l'Âme ; au cinq la Matière prime (hayûlâ, transcription du grec hylê), subordonnée à la Nature ; au six le Corps [du monde] (jism), subordonné à la Matière prime ; au sept la sphère la plus haute, subordonnée au Corps ; au huit les éléments (arkân), subordonnés à la sphère céleste ; au neuf, enfin, les trois genres d'existants engendrés (minéraux, végétaux, animaux), subordonnés aux éléments. Il conclut : « De même que le neuf est le dernier rang des unités, les genres engendrés sont le dernier rang des existants universels $»^{95}$. C'est toute la hiérarchie néoplatonicienne des êtres à partir de l'Un-Dieu qui se trouve attribuée à Pythagore.

Dans un dernier moment, Ashkevarî rapproche cette conception de l'un et du multiple de la doctrine, fréquemment condamnée comme hérétique par des docteurs shî‘ites aussi bien que sunnites, de «l'unicité de l'existence » (wahdat al-wujûd) ou du «monisme existentiel »d'Ibn 'Arabî. Tout comme le nombre n'est que le point de vue de la réitération et de la manifestation de l'un, la création dans son ensemble, dit-il, n'est qu'une multiplicité de miroirs reflétant l'unité absolue ou l'existence véritable de Dieu. Et de citer un propos d'Ibn 'Arabî qui ne déparerait pas une doxographie pythagoricienne :

Les réalités se mélangèrent et les nombres se manifestèrent par l'un dans les rangs [numériques] connus. L'un existentia le nombre et le nombre divisa l'un. Le décret du nombre ne se manifesta que par le nombré. Au sein du nombré, il y a de l'inexistence et de l'existence ; ainsi une chose peut être inexistante pour la sensation et existante pour l'intelligence. Il est donc nécessaire qu'il y ait du nombre et du nombré, comme il est nécessaire qu'il y ait l'un qui fasse naître cela et que cela naisse en raison de lui ${ }^{96}$.

\footnotetext{
${ }^{94}$ Ashkevarî, Maḥbûb, p. 210.

${ }^{95}$ Ibid., p. 210-211 ; Rasâ'il Ikhwân al-șafâ', 4 vol., Beyrouth, Dâr Șâdir, 2006, III, p. 178-182 (épître 32) ; Epistles of the Brethren of Purity. Sciences of the Soul and Intellect Part I; An Arabic Critical Edition and English Translation of Epistles 32-36, éd. et trad. angl. Paul E. Walker, Ismail K. Poonawala, David Simonowitz, and Godefroid de Callataÿ, Londres, I.B. Tauris, 2015, p. 5-10 du texte arabe, p. 17-19 de la traduction anglaise. Voir Y. Marquet, Les "Frères de la pureté » pythagoriciens de l'Islam, p. 220-224.

${ }^{96}$ Ashkevarî, Mahbûb, p. 210-211 ; cf. Ibn 'Arabî, Fuṣûs al-hikam, éd. Abû 1-'Alâ' ‘Afîfî, Beyrouth, Dâr al-kitâb al'arabî, 1423/2002, p. 77.
} 
Ainsi, l'attestation de l'unicité divine, chez Pythagore et ses émules en islam, va-t-elle de pair avec l'explication de la multiplicité observable dans la création. Sur celle-ci, d'autres vues pythagoriciennes sont encore adoptées par nos philosophes shî‘ites.

\section{L'homme microcosme}

Un premier thème d'origine (néo-)pythagoricienne, bien connu et déjà évoqué, est celui des correspondances entre l'homme comme microcosme et le monde comme macranthrope ${ }^{97}$. Mîr Dâmâd affirme :

Les plus grands sages enracinés [dans la science] (hukamâ-yi râsikhîn) ont tantôt appelé le monde «macranthrope» (insân kabîr) et l'homme «microcosme» ('âlam saghîr), tantôt l'homme « macrocosme » ('âlam kabîr) et le monde « micranthrope » (insân șaghîr). Ils l'ont expliqué en disant que, de tout ce que comprennent les couches des cercles du macrocosme, l'Instaurateur du " "Sois !" et elle est », le Démiurge du corps et de l'âme, a inséré un exemplaire dans le compas de l'être de l'homme. Ainsi la pie-mère (umm-i dimâgh), les couches des cavités et des ventricules cérébraux, sont en vis-àvis des sphères célestes $(. .$.$) ; les esprits psychiques et les puissances perceptives sont en vis-à-vis des$ anges préposés aux classes et aux rangs des sphères, parmi les intelligences et les âmes [des sphères] ; les quatre humeurs, les esprits animaux et les puissances naturelles sont en vis-à-vis des quatre éléments, des classes des choses matérielles et des anges préposés aux classes et aux cycles du monde matériel ; et les deux facultés de l'âme rationnelle - l'intellective et la pratique - sont [comme] le soleil et la lune ${ }^{98}$.

Il est remarquable que cette doctrine soit attribuée aux « sages enracinés », une allusion à l'expression coranique « ceux qui sont enracinés dans la Science » (al-râsikhûn fì l-'ilm) (III, 7), désignant, pour les shî‘ites, les philosophes et certains soufis, ceux qui partagent avec Dieu l'aptitude à interpréter la Révélation - soit les seuls imâms dans le shî‘isme originel. Pythagore se voit ainsi assimilé, avec d'autres sages anciens comme Démocrite, aux imâms-herméneutes de la Révélation, comme le confirme l'allusion au verset XXXVI, 82 : «Tel est, en vérité, son Ordre : quand Il veut une chose, Il lui dit "Sois !" et elle est ». Mîr Dâmâd développe la correspondance de

\footnotetext{
${ }^{97}$ Voir supra, p. 22. La formule : anthrôpos mikros kosmos est attribuée à Démocrite, qui aurait été l'élève des pythagoriciens, par David d'Alexandrie : Les écoles présocratiques, éd. et trad. Jean-Paul Dumont, Paris, Gallimard, 1991, p. 516. Le thème est introduit en islam par les Ikhwân al-Ṣafâ' dans leur épître intitulée « Sur le sens de la parole des sages selon laquelle le monde est un macranthrope » : Rasâ 'il Ikhwân al-Safầ', III, p. 212-230 (épître 34) ; Epistles of the Brethren of Purity. Sciences of the Soul and Intellect Part I, p. 51-104 du texte arabe, p. 81-108 de la traduction anglaise.

${ }^{98}$ Mîr Dâmâd, Jadhawât, p. 18.
} 
l'âme rationnelle avec le soleil et la lune par une analyse des deux éclipses pouvant advenir à l'âme, que reprend Ashkevarî dans sa notice sur Pythagore ${ }^{99}$.

Sur le même thème, Ashkevarî cite de Pythagore ce philosophème encore empreint de néoplatonisme :

[Pythagore] évoqua que l'homme, selon le décret de sa nature foncière, est posé en correspondance avec le monde entier. Il est un microcosme et le monde est un macranthrope. C'est pourquoi son lot [reçu] de l'Intellect et de l'Âme est si important. [L'homme] qui a bien raffermi son âme, corrigé ses mœurs et purifié ses états, peut parvenir à la connaissance du monde et de sa composition. Mais celui qui a négligé son âme [...] sort du compte du nombre et du nombré [...], se destine à la perte et à l'oubli.

Les anciens sages [...], qui agissaient suivant le contenu des Feuillets primordiaux, distinguaient par la vision intérieure que l'homme issu du sperme [cf. Coran, LXXV, 37] est le microcosme rassemblant tout ce qui se trouve dans le macranthrope qu'est le monde dans sa totalité. Du manuscrit de l'être (nuskhat al-wujûd), ils ont fait la plus belle lecture et la plus éloquente récitation des sublimes versets de leur Seigneur ${ }^{100}$.

Les anciens sages, à commencer par Pythagore, se seraient donc conformés pratiquement aux premiers Livres révélés ; toutefois, la configuration cosmique universelle de l'homme ne leur serait pas apparue par révélation, mais par «vision intérieure » (bașira). Ashkevarî ne manque pas l'occasion d'avérer cette conception par de célèbres vers attribués à l'imâm 'Alî :

Ton remède est en toi et tu ne comprends pas, ton mal vient de toi et tu ne le vois pas C'est toi qui es le livre clair (al-kitâb al-mubîn) [le Coran] dont les lettres manifestent le caché Tu prétends n'être qu'un petit corps quand le grand monde est enveloppé en toi ${ }^{101}$.

\section{L'âme harmonie}

Une autre thèse pythagoricienne esquissée plus haut, peut-être originellement liée à la précédente, est celle de l'âme comme harmonie ${ }^{102}$. Ashkevarî la présente et la justifie jusque dans son aspect le plus hétérodoxe, la préexistence des âmes, tout en l'associant à une vue religieuse attribuée ici à Pythagore en personne :

\footnotetext{
${ }^{99}$ Ibid., p. 18-21 ; Ashkevarî, Maḥbûb, p. 230-232 ; M. Terrier, Histoire de la sagesse, p. 399-401.

100 Ashkevarî, Mahbûb, p. 229. Source du premier paragraphe : U. Rudolph, Pseudo-Ammonios, p. 53-54.

${ }^{101}$ Ashkevarî, Maḥbûb, p. 230 ; Mîr Husayn Maybudî, Sharḥ-e Dîwân mansûb beh Amîr al-mu'minîn 'Alî b. Abî Tâlib, éd. Hasan Raḥmânî et Ibrâhim Ashk Shirin, Téhéran, Mirâth-e maktûb, 1390 h.s./2011, p. 456 et 458.

102 Attribuée à Pythagore et Philolaos par Macrobe ; voir Les écoles présocratiques, éd. et trad. J.-P. Dumont, p. 259. Sur cette théorie, voir Constantinos Macris, "Simmias de Thèbes », Dictionnaire des philosophes antiques, dir. Richard Goulet, t. VII, Paris, CNRS Éditions, 2018, p. 904-933, ici p. 919-933.
} 
Le sage Pythagore déclara: "L'âme humaine consiste en harmonies numériques et mélodiques (ta 'lîfât 'adadiyya wa lahnniyya), c'est pourquoi l'âme s'accorde avec les accords des mélodies et à leur écoute se délecte, s'étourdit, se passionne et s'émeut. Avant leur conjonction aux corps, les âmes sont instaurées à partir de ces harmonies numériques premières ; puis elles sont conjointes aux corps. Si les corrections morales sont accordées à la nature foncière et si les âmes sont dépouillées des accords extérieurs, elles s'unissent à leur propre monde et s'incorporent à une forme plus parfaite, plus belle que la première. Car les premières harmonies sont imparfaites sous un certain aspect, en tant qu'elles sont en puissance ; c'est par l'exercice et le combat spirituels (al-riyâda wa l-mujâhada) en ce monde qu'elles atteignent la limite de la perfection, en passant de la puissance à l'acte ». Il dit aussi : «Les Lois révélées (shara $\left.{ }^{\prime} i\right)$ qui fixent la mesure des prières, des aumônes et des autres actions de culte, visent seulement à synchroniser ces rapports avec ces harmonies spirituelles ${ }^{103}$.

La thèse de la préexistence des âmes, a priori inconvenante dans un contexte créationniste, peut être assumée par un penseur shî'ite car l'imâmologie admet la préexistence des esprits des imâms et de leurs fidèles ${ }^{104}$. Cette conception platonicienne reçoit un correctif aristotélicien avec l'idée que la conjonction corporelle et l'existence terrestre permettent le passage de la puissance à l'acte, et un complément d'éthique soufie avec la référence aux «exercices et combats spirituels ». L'ensemble est attribué à Pythagore qui apparaît une fois encore comme le plus synthétique et moderne des Anciens. Mais c'est surtout le devenir de l'âme après sa séparation de la Nature et du corps qui intéresse nos philosophes, et Pythagore a encore voix à ce dernier chapitre.

\section{Les fins dernières}

Les philosophes shî‘ites ont cherché chez les anciens Grecs, non seulement une théologie monothéiste rationnelle, mais aussi une théorie, au sens premier de vision contemplative, des fins de la création et de l'âme humaine, soit une eschatologie. Ashkevarî rapporte de Pythagore cette maxime : « De même qu'en Dieu est l'origine de notre existence et de notre constitution, de même vers Dieu le Très-Haut doivent se diriger nos âmes ${ }^{105}$. Il lui attribue aussi, comme à tous les sages divins et/ou métaphysiciens (al-ḥukamấ' al-ilâhîŷn), la thèse de la subsistance des âmes, de leur récompense ou de leur châtiment dans la vie dernière ${ }^{106}$. La récompense est celle-là même que Pythagore a expérimentée de son vivant: la conjonction au monde spirituel et lumineux,

\footnotetext{
${ }^{103}$ Ashkevarî, Mahbûb, p. 234 ; Mîr Dâmâd, Jadhawât, p. 134-135, cité plus haut. La source est Shahrastânî, Milal, II, p. 85-86 (Religions et sectes, II, p. 209).

${ }_{104}$ M. A. Amir-Moezzi, Le guide divin, p. 73-112.

${ }^{105}$ Ashkevarî, Mahbûb, p. 219.

${ }^{106}$ Ibid., p. 216.
} 
source de plaisirs merveilleux et éternels, à laquelle l'âme parvient en rejetant des vices de l'orgueil, de l'hypocrisie, de l'envie et des appétits corporels ${ }^{107}$. Quant au châtiment, la longue gnomologie de Pythagore n'en dit pas un mot.

Mullâ Șadrâ, dans son Épître sur la nouveauté du monde (fî hudûth al- 'âlam) se réfère d'abord à Pythagore pour réfuter la thèse de l'éternité du monde, que nous avons vu évitée par Mîr Dâmâd sous la formule de la « nouveauté anté-temporelle» :

On demanda [à Pythagore] : «Pourquoi as-tu affirmé l'annihilation du monde ? ». Il répondit : «Parce qu'il atteindra la cause en vue de laquelle il est, et quand il l'aura atteinte, son mouvement cessera ». Je dis que ce propos [...] semble avoir été tiré de la mine de la révélation et de la prophétie (ma'dan al-wahy wa-l-nubuwwa). Il indique la naissance de ce monde, son anéantissement et sa disparition [...], l'extinction de l'univers et l'advenue de la Grande résurrection [...].

Pythagore disait : "Ce qui est dans ce monde comprend une faible quantité de beauté, en tant qu'il est l'effet de la Nature. Les mondes qui sont au-dessus de lui sont de plus en plus éclatants, nobles et beaux, jusqu'à ce que la description parvienne au monde de l'Âme et de l'Intellect, où elle s'arrête, car il est impossible au langage de décrire ce que [l'Âme et l'Intellect] possèdent de noblesse, de magnificence, de beauté et de lustre. Consacrez votre ardeur et votre effort à rejoindre ce monde-là, afin que votre subsistance et votre permanence y soient durables, loin de la corruption et de la destruction; vous parviendrez à un monde qui est tout entier beauté, tout entier joie, tout entier puissance et vérité [...]. » Je dis que son discours exprime clairement que ce monde est corruptible, destructible, non susceptible de subsistance et de perpétuité. Tout ce qui est ainsi a son origine dans le néant et sa fin dans le néant ${ }^{108}$.

Dans son Épître sur l'Origine et le Retour (al-mabdâ' wa l-ma 'âd), Mullâ Șadrâ affirme encore que les sages anciens, à l'instar des prophètes et des imâms, ont soutenu et démontré par les actes la subsistance de l'âme individuelle après la destruction des corps ${ }^{109}$. Après avoir évoqué l'adresse de Moïse à ses compagnons («Revenez à votre Créateur et tuez-vous vous-mêmes ! : Coran, II, 54), la parole de Jésus à ses apôtres («Quand je me serai séparé de ce corps (haykal), je me tiendrai au ciel à la droite du Trône, entre les mains de mon père, votre père, intercédant pour vous » : écho de Matthieu, 28, 18-20), le martyre consenti par le troisième imâm al-Ḥusayn à Karbalâ' (en 61/680), le geste de Socrate buvant volontairement le poison, ainsi que diverses sentences de Platon et d'Aristote ${ }^{110}$, il ajoute :

\footnotetext{
107 Ibid., p. 215.

${ }^{108}$ Mullâ Șadrâ, Hudûth, p. 282-283.

${ }^{109}$ Mullâ Șadrâ, Al-Mabdâ' wa l-ma 'âd, éd. Muhammad Dhabîhî et Ja ‘far Shâh Naẓarî, Téhéran, Intishârât-e bonyâde hikmat-e islâmî-ye Șadrâ, 1381 h.s./2002-03, p. 528-532.

110 De ce dernier est citée l'Épitre de la pomme pseudépigraphique, une adaptation partielle du Phédon de Platon. Source : Rasâ'il Ikhwân al-șafâ', IV, p. 58 (épître 45) ; Epistles of the Brethren of Purity. On Companionship and Belief; An Arabic Critical Edition and English Translation of Epistles 43-45, éd. et trad. angl. Samer Traboulsi, Toby Mayer, and Ian R. Netton, Londres, I.B. Tauris, 2016, p. 133-134 du texte arabe, p. 137 de la traduction anglaise. Voir
} 
Ce qui montre que Pythagore, le maître du nombre - et parmi les plus éminents philosophes -, partageait cette vue, c'est son propos dans l'épître connue sous le titre des Recommandations en or (alwașâyâ al-dhahabiyya), qui est en notre possession. Dans sa recommandation à Diogène, il déclare à la fin : "Quand tu auras quitté ce corps pour te trouver affranchi (mukhallî) dans l'air, tu deviendras voyageur, tu ne reviendras plus à l'humanité et ne seras plus passible de la mort ${ }^{111}$.

Mullâ Șadrâ attribue aussi à Pythagore une exégèse des « livres » ou « feuillets » (suḥuf) qui, selon le Coran (versets XVII, 71 ; LXXIV, 52 ; LXXXI, 10), recensent les actions des hommes et seront déployés lors du Jugement dernier :

Parmi les paroles de Pythagore qui était l'un des plus grands sages devanciers : «Sache que tu seras confronté à tes actes, à tes paroles et à tes pensées. De chaque mouvement de la pensée, de la parole ou de l'action, se manifesteront pour toi des formes spirituelles et corporelles. Si le mouvement est [de l'âme] irascible ou concupiscible, il devient matière pour un démon qui te fera souffrir dans ta vie et te voilera la perception de la lumière après la mort. Si le mouvement est [de l'âme] intellectuelle, il devient un ange dont tu jouiras de la compagnie dans ce monde et qui te guidera dans la vie dernière jusqu'au voisinage de Dieu et de Sa grâce ${ }^{112}$.

C'est dire que la récompense et le châtiment, avec leur personnification sous la forme d'anges ou de démons, ont leur réalité dans le «monde imaginal » évoqué plus haut. Pythagore achève d'apparaître ici comme l'un de ces « sages enracinés dans la science » ayant vocation à pratiquer l'exégèse de la Révélation, précurseur de nos philosophes shî‘ites eux-mêmes.

\section{Conclusion}

Pythagore apparaît ainsi comme une référence majeure de la philosophie islamique shî'ite du $\mathrm{XI}^{\mathrm{e}} / \mathrm{XVII}{ }^{\mathrm{e}}$ siècle. Sa figure et ses idées, passées par le prisme néoplatonicien, ont servi de matériaux à des penseurs comme Mîr Dâmâd, Mullâ Șadrâ et Quṭb al-Dîn Ashkevarî pour réactiver un idéal de vie philosophique et religieuse - dans ses dimensions sociale, mystique et eschatologique - et

\footnotetext{
Mathieu Terrier, «La représentation de la sagesse grecque comme discours et mode de vie chez les philosophes shî'ites de l'Iran safavide (XI /XVII ${ }^{\mathrm{e}}$ siècle) », Studia graeco-arabica 5, 2015, p. 299-320, ici p. 316-317.

${ }^{111}$ Mullâ Șadrâ, Mabdâ', p. 532 ; Rasâ' 'il Ikhwân al-șafâ', IV, p. 35-36 (épître 44) ; Epistles of the Brethren of Purity. On Companionship and Belief, p. 81-82 du texte arabe, p. 106 de la traduction anglaise. Cf. Vers d'or, v. 70-71, dans Hiéroclès, Commentaire, p. 85. Sur l'importance de ces vers chez les commentateurs grecs et arabes, voir Anna Izdebska, «Man, God and the Apotheosis of Man in Greek and Arabic Commentaries to the Pythagorean Golden Verses », The International Journal of the Platonic Tradition 10, 2016, p. 40-64, ici p. 50-58.

112 Mullâ Șadrâ, Asrâr al-âyât, éd. Muḥammad Khwâjavî, Beyrouth, Dâr al-ṣafwa, 1413/1993, p. 205 ; Id., Mafâtih, II, p. 1041.
} 
construire une nouvelle théologie philosophique. Prenant au sérieux le récit selon lequel Pythagore tira sa sagesse de la «niche aux lumières de la prophétie », ces philosophes ont voulu démontrer l'accord de son enseignement avec celui des imâms, guides divins et maîtres de vérité des shî'ites, initiés par le « sceau des prophètes » Muhammad. Sans doute s'agissait-il pour eux de légitimer la philosophie auprès de leurs confrères juristes-théologiens, mais leur intention à peine voilée était surtout de rendre au shî‘isme la dimension spirituelle et ésotérique qu’ils tenaient pour essentielle, au moment même où cette religion connaissait une politisation et une institutionnalisation sans précédent en Iran safavide. Leur rapprochement systématique du corpus de Pythagore avec les hadîths des imâms et les versets du Coran ne relève ainsi ni d'un artifice rhétorique, ni d'un éclectisme concevant la vérité comme morcelée, mais bien de la conviction d'un accord foncier ou d'une symphônia entre la philosophie grecque et la Révélation. En cela, ces philosophes s'avèrent à la fois authentiquement shî'ites et profondément pythagoriciens.

met_terrier@yahoo.fr 